SUPPLEMENTARY INFORMATION FOR

\title{
An obligate peptidyl brominase underlies the discovery of highly distributed biosynthetic gene clusters in marine sponge microbiomes
}

\footnotetext{
Nguyet A. Nguyen, ${ }^{1}$ Zhenjian Lin, ${ }^{2}$ Ipsita Mohanty, ${ }^{1}$ Neha Garg, ${ }^{1}$ Eric W. Schmidt,${ }^{2}$ Vinayak Agarwal $1,3, *$ ${ }^{1}$ School of Chemistry and Biochemistry, Georgia Institute of Technology, Atlanta, Georgia 30332

${ }^{2}$ Department of Medicinal Chemistry, University of Utah, Salt Lake City, Utah 84112

${ }^{3}$ School of Biological Sciences, Georgia Institute of Technology, Atlanta, Georgia 30332

*Correspondence: vagarwal@gatech.edu
} 


\section{SuPPleMENTARY MATERIALS AND METHOdS}

\section{Metagenome sequencing, assembly, and binning}

Metagenomes from all sponge samples were sequenced using an Illumina HiSeq 2000 sequencer with $\sim 350$ bp inserts and 125 bp paired-end runs at the Huntsman Cancer Institute's High Throughput Genomics Center at the University of Utah. Illumina fastq reads were trimmed using Trimmomatic-0.39 (parameters PE phred33 ILLUMINACLIP: TruSeq3-PE-2.fa:2:30:10 LEADING:3 TRAILING:3 SLIDINGWINDOW:4:15 MINLEN:80. ${ }^{1}$ The trimmed reads were merged using BBMerge. ${ }^{2}$ Merged FASTA files were assembled using SPADES 3.14 with standard parameters in the Center for High Performance Computing at the University of Utah. ${ }^{3-4}$ Sequencing and assembly statistics can be found in Table S2.

All metagenomes were binned using Autometa. ${ }^{5}$ First, for contigs $\geq 1,000 \mathrm{bp}$, the taxonomic identity was predicted using make_taxonomy_table.py. Predicted bacterial and archaeal contigs were binned (with recruitment via supervised machine learning) using run_autometa.py. Bins that contained the $\operatorname{srp} E$ gene were screened by tblastn, and the $\operatorname{srp} E$ containing bins in each metagenome were classified using gtdb-tk. ${ }^{6}$ The relative abundance of each bin in terms of number of reads were estimated using the k-mer coverage from SPADES assembly in comparison with those of the total bacteria contigs identified by autometa algorithms.

\section{Genome wide average nucleotide identity (gANI) comparison and building BGC similarity networks}

Bacterial bins was pairwise compared using gANI and alignment fraction (AF) values with a cut-off of $\mathrm{AF}>0.7$ and $\mathrm{gANI}>0.9 .^{7-8}$ The gANI similarity were used to construct a network in Cytoscape. BGCs were predicted from the $\operatorname{srpE}$ containing contigs of each metagenome using antiSMASH 5.0. ${ }^{9}$ From these predictions, only BGCs with $\operatorname{srp} E$ gene were included in succeeding analyses. An all-versus-all comparison of these BGCs was performed using BiG-SCAPE. The similarity BGC network was constructed in Cytoscape. ${ }^{10}$

The parameters for running Big-SCAPE were: --include_singletons --mix --no_classify -cutoffs 0.1,0.25,0.3,0.5 --mode global. Networks for each distance cutoff values were examined manually and the network with cutoff $=0.3$ was selected.

\section{LC/MS data acquisition to inventory natural products in sponge extracts}

LC/MS datasets were generated based on procedure described before. ${ }^{11-12}$ In brief, frozen sponge tissues were lyophilized and extracted in 1:1 v/v DCM/MeOH for $48 \mathrm{~h}$ at room temperature. The clarified organic extract was dried, resuspended in $\mathrm{MeOH}$, and analyzed using an Agilent 1290 Infinity II ultra-performance liquid chromatography (UPLC) coupled to a Bruker ImpactII ultra-high-resolution Qq-ToF mass spectrometer equipped 
with an electron spray ionization source. A Kinetex $1.7 \mu \mathrm{m} \mathrm{C}_{18}$ reversed phase UPLC column $(50 \times 2.1 \mathrm{~mm})$ was employed for chromatographic separation. MS spectra were acquired in positive ionization mode, $m / z$ 50-2000 Da. An active exclusion of two spectra was employed with a release time window of $0.5 \mathrm{~min}$. For acquiring $\mathrm{MS}^{2}$ data, eight most intense ions per $\mathrm{MS}^{1}$ spectra were selected. The chromatographic separation was achieved using two solvents; solvent $\mathrm{A}$ : water $+0.1 \% \mathrm{v} / \mathrm{v}$ formic acid and solvent $\mathrm{B}$ : $\mathrm{MeCN}+0.1 \% \mathrm{v} / \mathrm{v}$ formic acid. Flow rate was held constant at $0.5 \mathrm{~mL} / \mathrm{min}$ throughout. The elution profile employed was: $5 \%$ solvent $\mathrm{B}$ for 3 min, a linear gradient from $5 \%$ to $50 \% \mathrm{~B}$ in $5 \mathrm{~min}, 50 \% \mathrm{~B}$ for $2 \mathrm{~min}$, from $50 \%$ to $100 \% \mathrm{~B}$ in $5 \mathrm{~min}, 100 \%$ B for $3 \mathrm{~min}$, from $100 \%$ to $5 \% \mathrm{~B}$ in $1 \mathrm{~min}, 5 \% \mathrm{~B}$ for $1 \mathrm{~min}$, from $5 \%$ to $100 \% \mathrm{~B}$ in $1 \mathrm{~min}, 100 \% \mathrm{~B}$ for $3 \mathrm{~min}$, from $100 \%$ to $5 \% \mathrm{~B}$ in $1 \mathrm{~min}, 5 \% \mathrm{~B}$ for $5 \mathrm{~min}$.

\section{Microbiome sequencing and analyses}

The v4 region of the 16S rRNA gene was used to query the microbial population associated with the sponges as described previously. ${ }^{11-12}$ The PCR reactions were performed with the primer pair 515F-806R (barcoded and appended with Illumina-specific adaptors) and Q5 high fidelity DNA polymerase. The thermocycling conditions were as follows: initial denaturation of $30 \mathrm{~s}$ at $98{ }^{\circ} \mathrm{C}, 35$ cycles each of $30 \mathrm{~s}$ at $98{ }^{\circ} \mathrm{C}, 30$ $\mathrm{s}$ at $50^{\circ} \mathrm{C}, 20 \mathrm{~s}$ at $72{ }^{\circ} \mathrm{C}$, and a final extension of $2 \mathrm{~min}$ at $72{ }^{\circ} \mathrm{C}$. Purified PCR amplicons were pooled in equimolar concentrations for sequencing on the Illumina MiSeq. The raw sequence reads were demultiplexed and sequence variants (SVs) were generated by QIIME2 using the qiime tools import script, qiime demux script and

the DADA2 plugin, ${ }^{13-14}$ respectively. Based on quality scores, the forward and reverse reads were truncated at 170 bp using the qiime dada2 denoise script. Taxonomy was assigned using the SILVA pre-trained classifier using the qiime feature classifier plug-in. ${ }^{15}$ The qiime taxa barplot script was used to generate the bar plots representing the taxonomic distribution. The $\alpha$-diversity of the microbiome was quantified by computing Shannon index using the q2_diversity plugin in QIIME2.

Preparation of constructs for expression of 1SrpE, TruE-LCCCW, OspA-LCCCW, and PoyA-LCCCW

The 1SrpE expression sequence was designed as:

\section{MGSS $\underline{H H H H H H H H H S S G L V P R G S H M R S G D D M L Q H L V E K S A L D A D F R Q Q L L A D P K S T I S Q E L G I S I P E ~}$ SMTIRVHESDMETVHLALPPDPNLTEEQLEAISAGLCCCW}

Here, the N-terminal $\mathrm{His}_{10}$ tag is underlined; the thrombin cleavage site is italicized; and the sequence encoded by gene $1 \operatorname{srp} E$ is in boldface. 
The gene was optimized for expression in E. coli and synthesized. Amplicons were generated by PCR using primers that incorporated restriction sites and the amplicon subcloned into pET28b(+) and pACYCDuet-1 vectors digested with NcoI and XhoI restriction enzymes. The E. coli strain DH5 $\alpha$ was used for transformations. Constructs were verified by Sanger sequencing. The truE-LCCCW, osp A-LCCCW, poyA-LCCCW, $1 S r p E-$ $L C C C G W$, and $1 S r p E-L C C C W G$ constructs were generated in an identical fashion.

\section{Preparation of constructs for expression of 1SrpC, 1SrpI, and $1 \mathrm{SrpT}_{1}{ }^{\text {protease }}$}

Genes optimized for expression in E. coli for $1 \operatorname{srp} C, 1 \operatorname{srpI}$, and $1 \operatorname{srp} T_{1}^{\text {protease }}$ were used as templates for amplification and subcloning of amplicons in plasmid vectors. $25 \mu \mathrm{L}$ PCR reactions contained 20 ng genomic DNA, $0.4 \mu \mathrm{M}$ each reverse and forward primers, $0.2 \mathrm{mM}$ dNTPs, Phusion reaction buffer and $0.25 \mathrm{U}$ Phusionhigh fidelity DNA polymerase. PCR amplicons were subcloned into plasmid vectors using Gibson Assembly HiFi master mix. Mutagenesis of $1 s r p E$ and $1 s r p I$ was performed using Primestar master mix. All constructs were verified by Sanger sequencing. For coexpression with $1 \operatorname{srp} E$, mutants thereof, or other substrate chimera genes, the modification enzyme encoding genes were subcloned without any appended affinity chromatography tags.

\section{Protein expression and purification}

For general heterologous expression, 20 ng plasmid DNA was transformed in E. coli BL21(DE3). Colonies were grown under appropriate antibiotic selection on LB agar media for $16 \mathrm{~h}$. A single colony was picked and inoculated in $10 \mathrm{~mL}$ of terrific broth (TB) supplemented with appropriate antibiotics for $16 \mathrm{~h}$ at $37^{\circ} \mathrm{C}$. This inoculum was used to initiate $1 \mathrm{~L}$ TB cultures supplemented corresponding antibiotics. Cultures were incubated with shaking at $30{ }^{\circ} \mathrm{C}$ until the $\mathrm{OD}_{600}$ reached 0.6 . Cultures were cooled at $18{ }^{\circ} \mathrm{C}$ for $1 \mathrm{~h}$ prior to induction of protein expression by the addition of $0.3 \mathrm{mM}$ isopropyl- $\beta$-d-thiogalactopyranoside (IPTG). Cultures were incubated at $18^{\circ} \mathrm{C}, 180 \mathrm{rpm}$ for $24 \mathrm{~h}$ for expression of LahT150, $1 \mathrm{SrpT}_{1}{ }^{\text {protease }}$, PfTrpB, and $1 \mathrm{SrpE}$. Cultures were incubated at $18{ }^{\circ} \mathrm{C}, 180 \mathrm{rpm}$ for $48 \mathrm{~h}$ when gene $1 \operatorname{srpE}$ (or mutants thereof) was coexpressed with the $1 \operatorname{srpC} / 1 \operatorname{srpI}$.

For purification of NHis $10-1 \mathrm{SrpE}$, culture was harvested by centrifugation $\left(7,000 \times \mathrm{g}, 25 \mathrm{~min}, 4{ }^{\circ} \mathrm{C}\right)$ and resuspended in $50 \mathrm{~mL}$ lysis buffer (20 Na-phosphate ( $\mathrm{pH} 7.5), 50 \mathrm{mM} \mathrm{NaCl})$. Cells were lysed by sonication and the lysate was clarified by centrifugation at $30,000 \times \mathrm{g}$ for $45 \mathrm{~min}$ at $4{ }^{\circ} \mathrm{C}$. The supernatant was loaded on to a 5 mL His-Trap Ni-NTA column equilibrated with the lysis buffer. The column was washed with wash buffer (20 $\mathrm{mM}$ Na-phosphate ( $\mathrm{pH} 7.5), 50 \mathrm{mM} \mathrm{NaCl}, 30 \mathrm{mM}$ imidazole) and bound proteins were then eluted using elution buffer (20 mM Na-phosphate (pH 7.5), $50 \mathrm{mM} \mathrm{NaCl}, 1 \mathrm{M}$ imidazole) in three fractions of $5 \mathrm{~mL}$ volume each for a total volume of $15 \mathrm{~mL}$. Each fraction was checked by MALDI-ToF mass spectrometry (see below). The second 
fraction was found to contain the majority of the $1 \mathrm{SrpE}$ peptide. The second fraction was then desalted by Sephadex G-25 PD10 column as per the manufacturer's instructions. The peptide concentration was measured by Bradford assay. Aliquots were frozen in liquid nitrogen and stored at $-80^{\circ} \mathrm{C}$ for future use.

For purification of $\mathrm{NHis}_{6}-\mathrm{SrpT}_{1}{ }^{\text {protease }}$ and $\mathrm{NHis}_{6}$-LahT150, cultures were harvested by centrifugation as before and cell pellets were resuspended in lysis buffer (20 mM Tris-Cl (pH 8.0), $500 \mathrm{mM} \mathrm{NaCl})$. Cells were lysed by sonication. The lysate was clarified by centrifugation at $30,000 \times \mathrm{g}$ for $45 \mathrm{~min}$, and the supernatant was loaded on to a $5 \mathrm{~mL}$ His-Trap Ni-NTA column. Column was washed extensively with wash buffer (20 mM Tris$\mathrm{Cl}$ (pH 8.0), $500 \mathrm{mM} \mathrm{NaCl}, 30 \mathrm{mM}$ imidazole) and protein was eluted using a linear gradient to elution buffer (20 $\mathrm{mM}$ Tris-Cl (pH 8.0), $500 \mathrm{mM} \mathrm{NaCl}, 250 \mathrm{mM}$ imidazole). Purity of eluent fractions were checked by SDS-

PAGE, and fractions containing protein of interest were pooled and desalted using Sephadex G-25 PD10 columns in storage buffer (20 mM HEPES-Na (pH 7.5), $50 \mathrm{mM} \mathrm{KCl,} \mathrm{10 \%} \mathrm{glycerol).} \mathrm{Protein} \mathrm{concentrations} \mathrm{were}$ measured by Bradford assay and aliquots were frozen in liquid nitrogen and stored at $-80{ }^{\circ} \mathrm{C}$ for future use.

For purification of $P f \operatorname{TrpB}, 1 \mathrm{~L}$ expression culture was harvested by centrifugation and cell pellet was resuspended in lysis buffer (25 mM K-phosphate ( $\mathrm{pH} 8.0$ ), $100 \mathrm{mM} \mathrm{NaCl}, 200 \mu \mathrm{M}$ pyridoxal phosphate). Cells were lysed by sonication and the lysate was clarified by centrifugation at $30,000 \times \mathrm{g}$ for $45 \mathrm{~min}$. The supernatant was loaded on to a $5 \mathrm{~mL}$ His-Trap Ni-NTA column. Column was washed with binding buffer. The protein was eluted with elution buffer (25 mM K-phosphate (pH 8.0), $100 \mathrm{mM} \mathrm{NaCl}, 50 \mathrm{mM}$ imidazole). Purity of eluant were checked using SDS-PAGE, and fractions containing protein of interest were pooled and desalted using dialysis against binding buffer. Protein concentration was measured using Bradford assay. Aliquots were frozen in liquid nitrogen and stored at $-80^{\circ} \mathrm{C}$ for future use.

For cultures involving co-expression of $1 \mathrm{SrpE}$ and mutants thereof with $1 \mathrm{SrpC} / 1 \mathrm{SrpI}$, cells were harvested by centrifugation $\left(7,000 \times \mathrm{g}, 25 \mathrm{~min}, 4^{\circ} \mathrm{C}\right)$ and resuspended in $50 \mathrm{~mL}$ lysis buffer $(20 \mathrm{mM}$ Na-phosphate ( $\mathrm{pH} 7.5), 6 \mathrm{M}$ guanidine hydrochloride ( $\mathrm{Gdn}-\mathrm{HCl}), 50 \mathrm{mM} \mathrm{NaCl}$ ). Cells were lysed by sonication and the lysate was clarified by centrifugation at $30,000 \times \mathrm{g}$ for $45 \mathrm{~min}$. The supernatant was loaded on to a $5 \mathrm{~mL}$ His-Trap NiNTA column. The column was washed with wash buffer (20 mM Na- phosphate (pH 7.5), $50 \mathrm{mM} \mathrm{NaCl}, 30 \mathrm{mM}$ imidazole) and bound proteins were eluted using elution buffer (20 mM Na- phosphate (pH 7.5), $50 \mathrm{mM} \mathrm{NaCl}, 1$ $\mathrm{M}$ imidazole) in three fractions of $5 \mathrm{~mL}$ each for a total volume of $15 \mathrm{~mL}$. The second fraction was directly used for other assays or analysis by mass spectrometry. Aliquots were frozen and stored at $-80{ }^{\circ} \mathrm{C}$ for future use.

\section{In vitro peptidase assays}

$1 \mathrm{SrpT}_{1}{ }^{\text {protease }}$ cleavage reaction was performed in $200 \mu \mathrm{L}$ volume at $30^{\circ} \mathrm{C}$ overnight. The reaction contained $50 \mathrm{mM}$ HEPES-Na (pH 7.5), $5 \mathrm{mM}$ DTT, $100 \mu \mathrm{M} 1 \mathrm{SrpT}_{1}{ }^{\text {protease }}$, and $50 \mu \mathrm{M}$ substrate peptide. LahT150 
cleavage assays were performed in $200 \mu \mathrm{L}$ volume and contained $50 \mathrm{mM}$ HEPES-Na (pH 7.5), $5 \mathrm{mM}$ DTT, 20 $\mu \mathrm{M}$ LahT150 and up to $200 \mu \mathrm{M}$ purified peptides. Reactions were incubated at $30{ }^{\circ} \mathrm{C}$ for $2.5 \mathrm{~h}$. Peptidase reactions with $1 \mathrm{SrpT}_{1}{ }^{\text {protease }}$ or LahT150 were quenched by addition of $50 \mu \mathrm{L} 5 \% \mathrm{v} / \mathrm{v}$ trichloroacetic acid (TCA) in $\mathrm{MeOH}$ and centrifugated to remove precipitates. The supernatants were analyzed by LC/MS using protocols detailed below. Peptide digestion with LysC was performed by adding $1 \mu \mathrm{L} 0.2 \mathrm{mg} / \mathrm{mL}$ LysC protease to $200 \mu \mathrm{L}$ of purified peptides incubation at $30^{\circ} \mathrm{C}$ for $90 \mathrm{~min}$. The reaction was then desalted and analyzed by MALDI-ToF mass spectrometry (protocols detailed below). Reactions involving carboxypeptidase A contained $0.1 \mathrm{U} / \mathrm{mL}$ carboxypeptidase A, $50 \mathrm{mM}$ Tris- $\mathrm{Cl}$ (pH 7.5), $300 \mathrm{mM} \mathrm{NaCl}$, and $300 \mu \mathrm{M}$ purified $1 \mathrm{SrpE}$. The reaction was incubated at $30^{\circ} \mathrm{C}$ for $2 \mathrm{~h}$. The reaction was then quenched by an equal volume of $1: 1 \mathrm{HCl}(1 \mathrm{M}): \mathrm{MeOH}$, and centrifugated to remove precipitates. The supernatant was analyzed by LC/MS as detailed below.

For labeling of cysteine thiols with iodoacetamide, after digestion with LahT150 for $2.5 \mathrm{~h}, 50 \mathrm{mM}$ Tris-Cl ( $\mathrm{pH} 8.0$ ) and $50 \mathrm{mM}$ iodoacetamide were added to the reaction. The iodoacetamide labeling reaction was performed overnight in dark at $25^{\circ} \mathrm{C}$. The reaction mixture was clarified by centrifugation and analyzed by LC/MS.

\section{Synthesis of 2-, 4-, 5-,6- and 7-bromo-L-tryptophan}

The protocol to synthesize 2-bromo-L-tryptophan were adapted from Bhandari et al. ${ }^{16} \mathrm{In}$ a $10 \mathrm{~mL}$ round bottom flask, $130 \mathrm{mg}$ L-Trp methyl ester $(0.51 \mathrm{mmol})$ was dissolved in $5 \mathrm{~mL}$ of glacial acetic acid and $1.5 \mathrm{~mL}$ formic acid. To this, $92.5 \mathrm{mg}$ N-bromosuccinimide $(0.52 \mathrm{mmol})$ was added. The reaction was allowed to proceed at room temperature for $30 \mathrm{~min}$. Solvents were then removed in vacuo. The product was purified by isocratic silica column chromatography using 95:5 DCM:MeOH to yield 2-bromotryptophan methyl ester. The ester was hydrolyzed by $\alpha$-chymotrypsin. The $\alpha$-chymotrypsin cleavage reaction contained $2 \mathrm{mM} 2$-bromo-L-tryptophan methyl ester and $0.5 \mathrm{mg} / \mathrm{mL}$ chymotrypsin in $50 \mathrm{mM}$ Tris- $\mathrm{Cl}(\mathrm{pH} 7.5)$. The reaction was incubated at $25^{\circ} \mathrm{C}$ for $2.5 \mathrm{~h}$ and quenched by addition of equal volume of $1: 1 \mathrm{HCl}(1 \mathrm{M}): \mathrm{MeOH}$ and centrifuged to remove precipitates. The supernatant was analyzed by LC/MS in the positive ionization mode.

The synthesis of 4-, 5-,6- and 7-bromo-L-tryptophan were performed enzymatically using the tryptophan halogenase $P f \operatorname{TrpB} .{ }^{17}$ The reaction contained $1 \mathrm{mM}$ 4-, 5-, 6-, or 7-bromo indole and $1 \mathrm{mM}$ L-serine in $100 \mathrm{mM}$ potassium phosphate buffer ( $\mathrm{pH} 8.0$ ). Reaction was initiated by addition of $5 \mu \mathrm{M}$ purified PfTrpB. The reaction mixture was incubated at $75{ }^{\circ} \mathrm{C}$ for $20 \mathrm{~h}$. The reaction was then quenched by addition of equal volume of $1: 1 \mathrm{HCl}$ ( $1 \mathrm{M}): \mathrm{MeOH}$, and centrifugated to remove precipitates. The supernatant was analyzed by LC/MS in the positive ionization mode. 


\section{Mass spectrometry}

For MALDI-ToF mass spectrometry after LysC digestion of purified 1SrpE, reactions samples were desalted using $\mathrm{C}_{18}$ ZipTips (Sigma) and spotted on a MALDI target using $2 \mu \mathrm{L}$ saturated sinapinic acid (Sigma) in 7:3:0.1 MeCN:H $\mathrm{H}_{2} \mathrm{O}:$ TFA for analyses by a rapifleX MALDI-ToF mass spectrometer (Bruker Daltonics) in positive ionization mode. The data were analyzed using flexAnalysis software.

For assays monitoring cleavage of $1 \mathrm{SrpE}$ by $\mathrm{LahT} 150$ or $1 \mathrm{SrpT}_{1}{ }^{\text {protease }}$, the reaction products were analyzed using 1290 Infinity II UHPLC system (Agilent Technologies) coupled to a high-resolution Impact II QqTOF mass spectrometer (Bruker Daltonics). Mass spectrometry data were collected in the positive ionization mode in the mass range $m / z$ 100-2000 Da. Samples were analyzed using Kinetex ${ }^{\mathrm{TM}} 1.7 \mu \mathrm{m}$ C18 reversed phase UHPLC column $(50 \times 2.1 \mathrm{~mm})$ at a flow rate of $0.5 \mathrm{~mL} / \mathrm{min}$ and the chromatographic separation was achieved using solvent $\mathrm{A}: \mathrm{H}_{2} \mathrm{O}+0.1 \%(\mathrm{v} / \mathrm{v})$ formic acid, and solvent $\mathrm{B}$ : $\mathrm{MeCN}+0.1 \%(\mathrm{v} / \mathrm{v})$ formic acid. The chromatography profile was as follows: 5\% solvent B from 0-5 min, linear gradient to $75 \%$ solvent B from 5-30 min, linear gradient to $95 \%$ solvent B from $30-31 \mathrm{~min}, 95 \%$ solvent B from $31-35 \mathrm{~min}$, linear gradient to $5 \%$ solvent B from 35-36 min, 5\% solvent B from 36-38 min, linear gradient to 95\% solvent B from 38-39 min, 95\% solvent B from 39-42 min, and linear gradient to 5\% solvent B from 42-43 min.

The bromotryptophan standards and the excision product generated by carboxypeptidase A were analyzed by Bruker amaZon SL ion trap mass spectrometer coupled to an Agilent 1260 HPLC. Mass spectrometry data were collected in the positive ionization mode in the mass range $m / z$ 100-1000 Da. Chromatography was performed using Luna ${ }^{\circledR} 5 \mu \mathrm{m}$ C18 reversed phase HPLC column $(100 \times 4.6 \mathrm{~mm})$ at a flow rate of $0.5 \mathrm{~mL} / \mathrm{min}$; solvent $\mathrm{A}: \mathrm{H}_{2} \mathrm{O}+0.1 \% \mathrm{v} / \mathrm{v}$ formic acid, solvent $\mathrm{B}: \mathrm{MeCN}+0.1 \% \mathrm{v} / \mathrm{v}$ formic acid. The chromatography elution profile was as follows: $4 \%$ solvent B from 0-3 min, linear gradient to $20 \%$ solvent B from 3-8 min, linear gradient to $45 \%$ solvent B from 8-33 min, linear gradient to $100 \%$ solvent B from $33-35 \mathrm{~min}, 100 \%$ solvent B from 38-39 min, 100\% solvent B from 39-40 min, and linear gradient to 5\% solvent B from 40-41 min. 


\section{SUPPLEMENTARY TABLES}

Table S1. Assignment of sponge phylogeny based on consensus ITS-2 and 28S sequences

\begin{tabular}{|c|c|c|c|c|}
\hline Order & Family & Genus $^{\dagger}$ & $\begin{array}{l}\text { Natural product } \\
\text { class }\end{array}$ & $\begin{array}{l}\text { Geographical } \\
\text { location }\end{array}$ \\
\hline Verongiida & Aplysinidae & Aplysina-1 & Bromotyrosines $^{18}$ & Florida Keys \\
\hline Verongiida & Aplysinidae & Aplysina-2 & Bromotyrosines $^{18}$ & Florida Keys \\
\hline Dictyoceratida & Thorectidae & Smenospongia & Bromoindoles $^{19}$ & Florida Keys \\
\hline Verongiida & Aplysinidae & Verongula & Bromotyrosines $^{18}$ & Florida Keys \\
\hline Verongiida & Aplysinidae & Aiolochroia & Bromotyrosines $^{18}$ & Florida Keys \\
\hline Verongiida & Aplysinidae & Aplysina-3 & Bromotyrosines $^{18}$ & Florida Keys \\
\hline Verongiida & Pseudoceratinidae & Pseudoceratina-1 & Bromotyrosines $^{18}$ & Puerto Rico \\
\hline Verongiida & Pseudoceratinidae & Pseudoceratina-2 & Bromotyrosines $^{18}$ & Puerto Rico \\
\hline Verongiida & Aplysinidae & Aplysina & Bromotyrosines $^{18}$ & Puerto Rico \\
\hline Verongiida & Aplysinidae & Aiolochroia & Bromotyrosines $^{18}$ & Puerto Rico \\
\hline Verongiida & Ianthellidae & Ianthella & Bastadins $^{18}$ & Guam \\
\hline Verongiida & Ianthellidae & Aplysinella & Psammaplins $^{18}$ & Guam \\
\hline Dictyoceratida & Irciniidae & Ircinia-1 & Meroterpenoids $^{\S}$ & Solomon Islands \\
\hline Dictyoceratida & Irciniidae & Ircinia-2 & Meroterpenoids $^{\S}$ & Solomon Islands \\
\hline
\end{tabular}

†In this study, we are restricting a description of sponge phylogeny to the genus level. We have demonstrated previously that ITS-2 and 28S amplicon sequences are unable to differentiate sponge species. ${ }^{18,20-21}$ Sponges with identical amplicon sequences can have drastically different morphologies. ${ }^{21}$

${ }^{\S}$ LC-MS data has been deposited in the MassIVE repository (MSV000086758). 
Table S2. Metagenomic sequencing and assembly results

\begin{tabular}{|c|c|c|c|c|c|c|c|c|}
\hline $\begin{array}{l}\text { Accession } \\
\text { number }\end{array}$ & $\begin{array}{l}\text { Sponge } \\
\text { sample }\end{array}$ & $\begin{array}{l}\text { Total } \\
\text { assembly } \\
\text { size (bp) }\end{array}$ & $\begin{array}{l}\text { Number } \\
\text { of } \\
\text { contigs }\end{array}$ & $\begin{array}{l}\text { N25 } \\
\text { (bp) }\end{array}$ & $\begin{array}{l}\text { N50 } \\
\text { (bp) }\end{array}$ & $\begin{array}{l}\text { N75 } \\
\text { (bp) }\end{array}$ & $\begin{array}{l}\text { GC } \\
\%\end{array}$ & $\begin{array}{l}\text { SRA } \\
\text { accession }\end{array}$ \\
\hline SRR13587057 & Aplysina-1 $\left(\mathrm{FK}^{1}\right)$ & $1,278,067,056$ & 817,216 & 12,623 & 3,120 & 1,028 & 57.46 & $13801 \mathrm{X} 1$ \\
\hline SRR13587056 & Aplysina-2 (FK) & $1,406,144,275$ & 873,416 & 10,162 & 3,227 & 1,093 & 57.55 & 13801X6 \\
\hline SRR13587053 & S. aurea $(\mathrm{FK})$ & $1,035,878,068$ & 398,161 & 70,637 & 14,257 & 2,322 & 59.72 & 14317X1 \\
\hline SRR13587052 & Verongula $(\mathrm{FK})$ & $1,202,310,381$ & 816,387 & 10,389 & 2,979 & 9,38 & 56.23 & $13801 \times 5$ \\
\hline SRR13587051 & Aiolochroia (FK) & $1,106,175,294$ & 711,257 & 10,252 & 3,138 & 1,041 & 57.14 & $13801 X 4$ \\
\hline SRR13587050 & Aplysina-3 (FK) & $1,119,533,618$ & 440,303 & 43,163 & 7,942 & 2,135 & 58.28 & $14317 X 3$ \\
\hline SRR13587049 & $\begin{array}{l}\text { Pseudoceratina-1 } \\
\left(\mathrm{PR}^{2}\right)\end{array}$ & $1,018,954,140$ & 673,905 & 10,800 & 3,184 & 1,020 & 56.06 & $14317 X 9$ \\
\hline SRR13587048 & $\begin{array}{l}\text { Pseudoceratina-2 } \\
(\mathrm{PR})\end{array}$ & $912,809,883$ & 572,070 & 12,772 & 3,284 & 1,105 & 55.48 & $14317 \times 10$ \\
\hline SRR13587047 & Aplysina (PR) & $1,328,795,944$ & $1,023,476$ & 7,897 & 2,034 & 852 & 50.16 & $14317 X 11$ \\
\hline SRR13587046 & Aiolochroia (PR) & $1,082,417,825$ & 405,222 & 54,827 & 9,334 & 2,331 & 58.44 & $14317 \times 12$ \\
\hline SRR13587055 & Ircinia-1 $\left(\mathrm{SI}^{3}\right)$ & $1,451,958,833$ & 645,547 & 52,531 & 8,171 & 2,435 & 51.56 & $15716 \times 1$ \\
\hline SRR13587054 & Ircinia-2 (SI) & $1,287,094,131$ & 902,899 & 57,539 & 4,389 & 1,147 & 52.31 & $15658 \mathrm{X} 1$ \\
\hline
\end{tabular}

${ }^{1}$ FK: Florida Keys; ${ }^{2}$ PR: Puerto Rico; ${ }^{3}$ SI: Solomon Islands 
Table S3. Phylum assignments for bacterial taxa possessing srp BGCs

\begin{tabular}{|c|c|c|}
\hline & Sponge genera & Bacterial phyla \\
\hline group_1 & $\begin{array}{l}\text { Aiolochroia; Aplysina; Ircinia; Pseudoceratina; Smenospongia; } \\
\text { Verongula }\end{array}$ & Latescibacterota \\
\hline group_2 & $\begin{array}{l}\text { Aiolochroia; Aplysina; Ircinia; Pseudoceratina; Smenospongia; } \\
\text { Verongula }\end{array}$ & UBA 8248 \\
\hline group_3 & $\begin{array}{l}\text { Aiolochroia; Aplysina; Ircinia; Pseudoceratina; Smenospongia; } \\
\text { Verongula }\end{array}$ & Nitrospirota \\
\hline group_ 4 & Aiolochroia; Aplysina; Ircinia; Smenospongia; Verongula & Proteobacteria \\
\hline group_5 & Aplysina; Ircinia; Smenospongia; Verongula & Proteobacteria \\
\hline group_6 & Aiolochroia; Aplysina; Ircinia; Pseudoceratina; Verongula & Acidobacteriota \\
\hline group_7 & $\begin{array}{l}\text { Aiolochroia; Aplysina; Ircinia; Pseudoceratina; Smenospongia; } \\
\text { Verongula }\end{array}$ & Acidobacteriota \\
\hline group 8 & Aplysina; Ircinia; Smenospongia; Verongula & Acidobacteriota \\
\hline group 9 & Aiolochroia; Aplysina; Ircinia & Proteobacteria \\
\hline group 10 & Aiolochroia; Aplysina; Ircinia & Proteobacteria \\
\hline group_11 & Aplysina; Pseudoceratina; Smenospongia; Verongula & Proteobacteria \\
\hline group 12 & Aplysina; Ircinia; Pseudoceratina & Acidobacteriota \\
\hline group 13 & Aplysina; Pseudoceratina; Smenospongia & Proteobacteria \\
\hline group_14 & Aiolochroia; Aplysina; Ircinia & Proteobacteria \\
\hline group_15 & Aiolochroia; Aplysina; Ircinia & Proteobacteria \\
\hline group 16 & Aiolochroia; Aplysina; Smenospongia & Proteobacteria \\
\hline group_17 & Aplysina; Ircinia; Pseudoceratina; Smenospongia & Proteobacteria \\
\hline group 18 & Aplysina; Ircinia; Smenospongia & Proteobacteria \\
\hline group_19 & Aiolochroia; Pseudoceratina; Verongula & Verrucomicrobiota \\
\hline group_20 & Ircinia; Pseudoceratina; Smenospongia; Verongula & Proteobacteria \\
\hline group 21 & Aiolochroia; Ircinia & Proteobacteria \\
\hline group_22 & Aplysina; Pseudoceratina & Proteobacteria \\
\hline group_23 & Aplysina; Ircinia & Acidobacteriota \\
\hline group_ 24 & Aiolochroia; Aplysina; Verongula & Proteobacteria \\
\hline group_25 & Aplysina; Pseudoceratina; Smenospongia & Proteobacteria \\
\hline group_26 & Aplysina; Smenospongia; Verongula & Chloroflexota B \\
\hline group 27 & Ircinia; Smenospongia & Binatota \\
\hline group_28 & Aplysina; Verongula & Acidobacteriota \\
\hline group_29 & Aiolochroia; Aplysina; Verongula & Acidobacteriota \\
\hline group_ 30 & Aiolochroia; Ircinia; Smenospongia & Proteobacteria \\
\hline group 31 & Aiolochroia; Aplysina; Verongula & Acidobacteriota \\
\hline group_32 & Aplysina; Pseudoceratina; Smenospongia & Proteobacteria \\
\hline group 33 & Aplysina; Ircinia; Pseudoceratina & Proteobacteria \\
\hline group 34 & Aplysina; Ircinia; Smenospongia & Proteobacteria \\
\hline group_35 & Aiolochroia; Ircinia; Smenospongia & Proteobacteria \\
\hline group 36 & Ircinia; Smenospongia & Proteobacteria \\
\hline group 37 & Aplysina; Ircinia & Proteobacteria \\
\hline group_38 & Aplysina & Proteobacteria \\
\hline group 39 & Aplysina; Verongula & Proteobacteria \\
\hline group 40 & Aplysina & Proteobacteria \\
\hline group_41 & Verongula & Gemmatimonadota \\
\hline group 42 & Aiolochroia; Verongula & Proteobacteria \\
\hline group 43 & Aiolochroia;Pseudoceratina & Proteobacteria \\
\hline group_44 & Aiolochroia; Aplysina & Acidobacteriota \\
\hline group 45 & Aiolochroia;Aplysina & Proteobacteria \\
\hline
\end{tabular}




\section{SUPPLEMENTARY FIGURES}

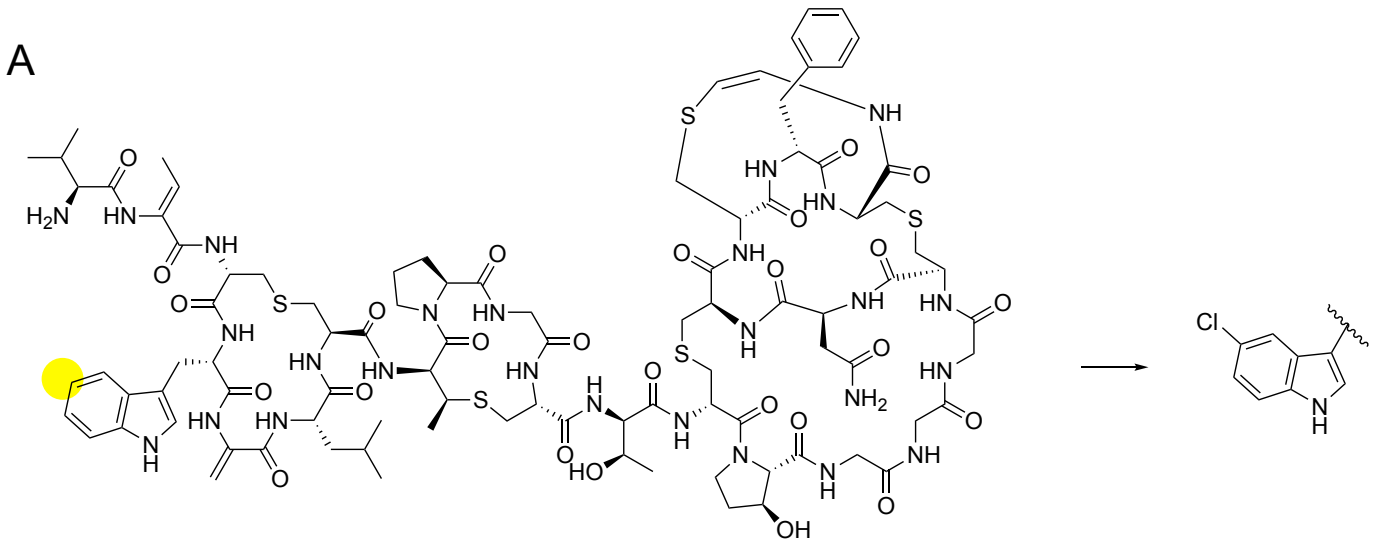

B

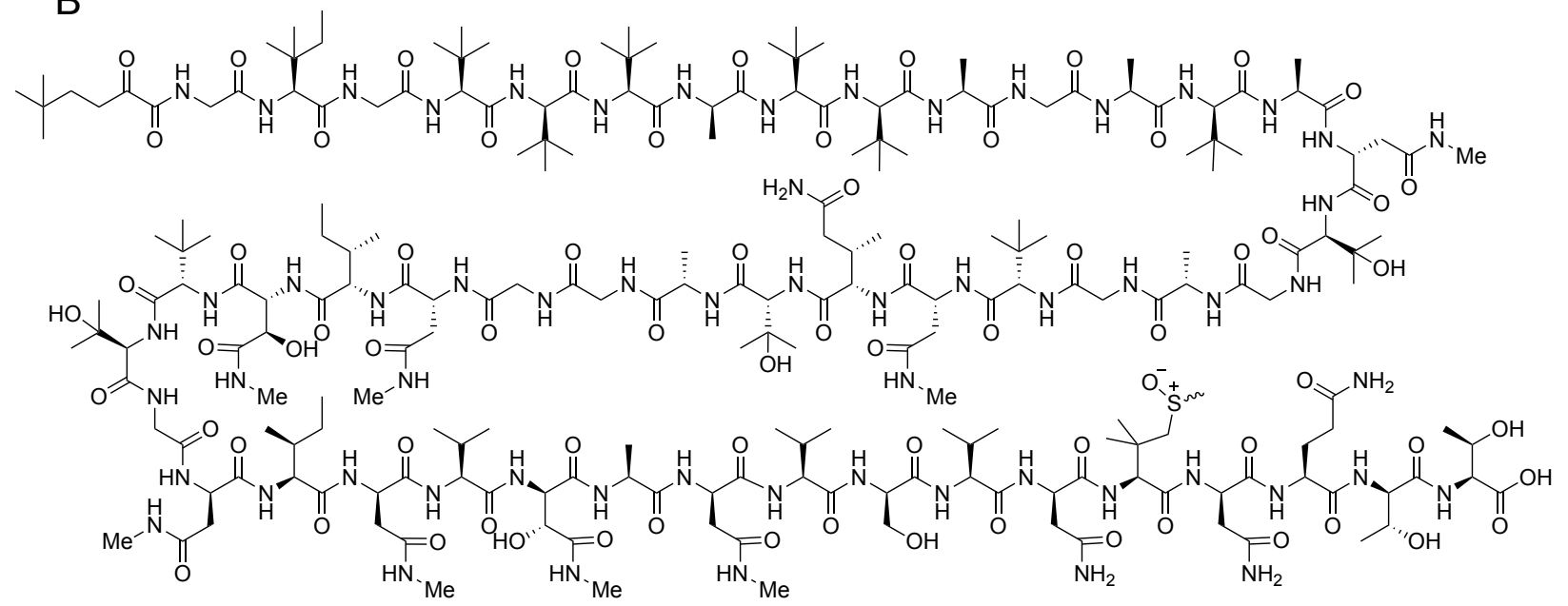

C

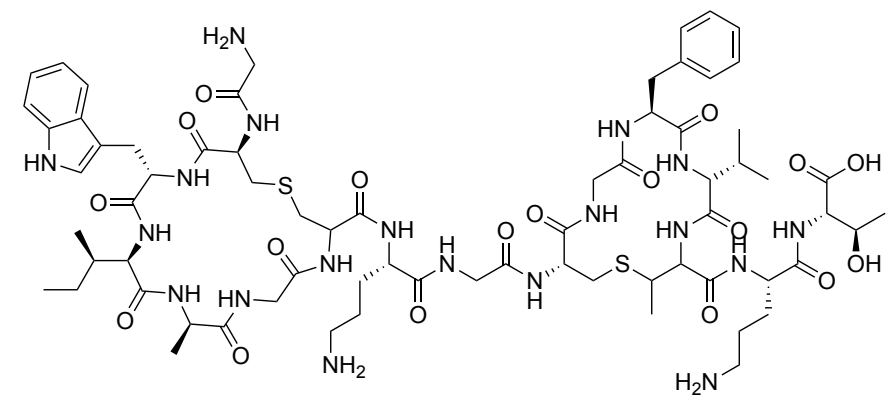

Fig. S1. (A) Chlorination reaction catalyzed by MibH. Note that the MibH substrate is a highly modified RiPP core that has already been removed from the leader peptide. Chemical structures of proteusin RiPPs (B) polytheonamide B and $(\mathbf{C})$ landornamide. Polytheonamides and landornamides do not bear azol(in)e heterocycles or halogenated residues. 


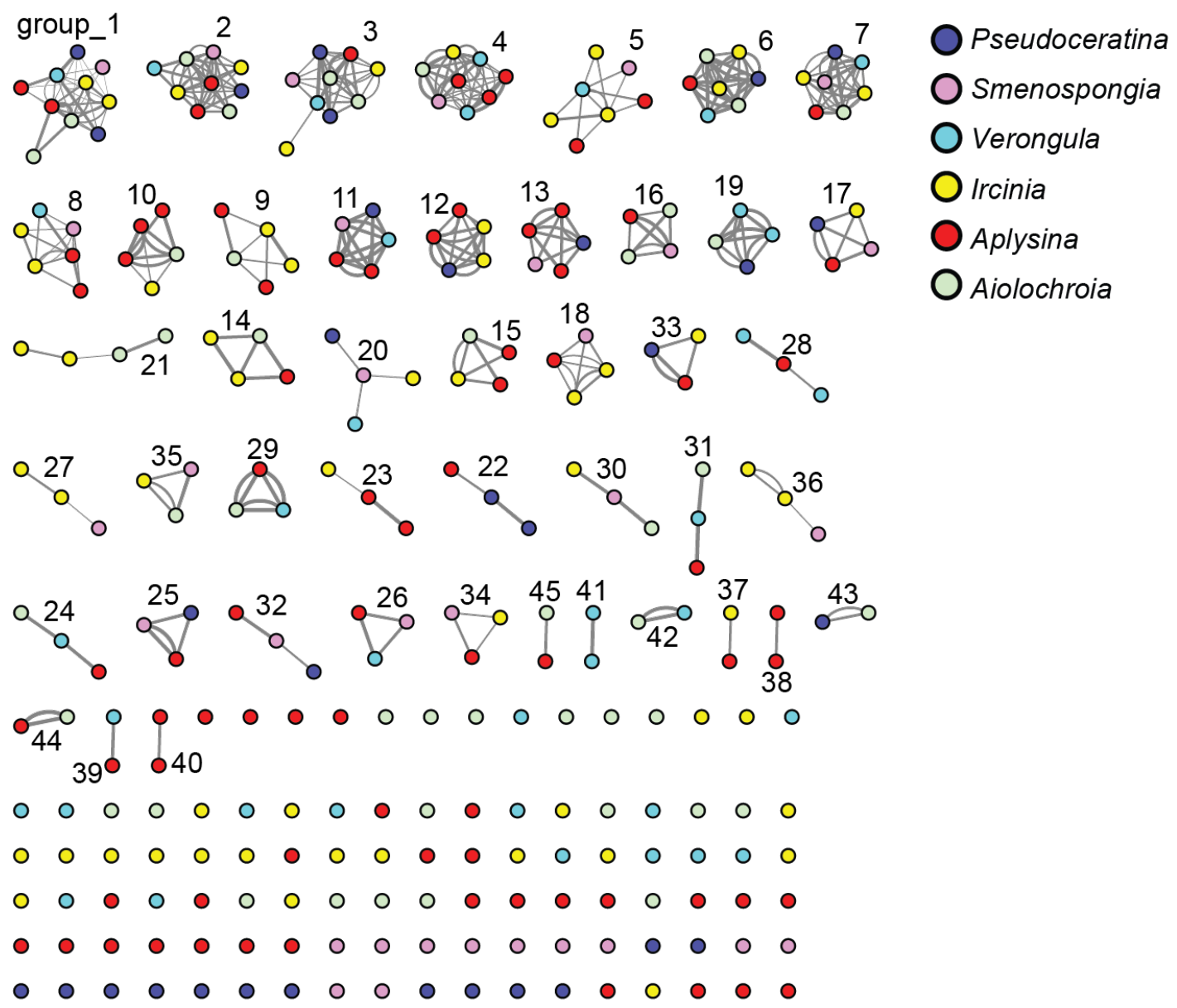

Fig. S2. Genome-wide average nucleotide identity (gANI) network. 


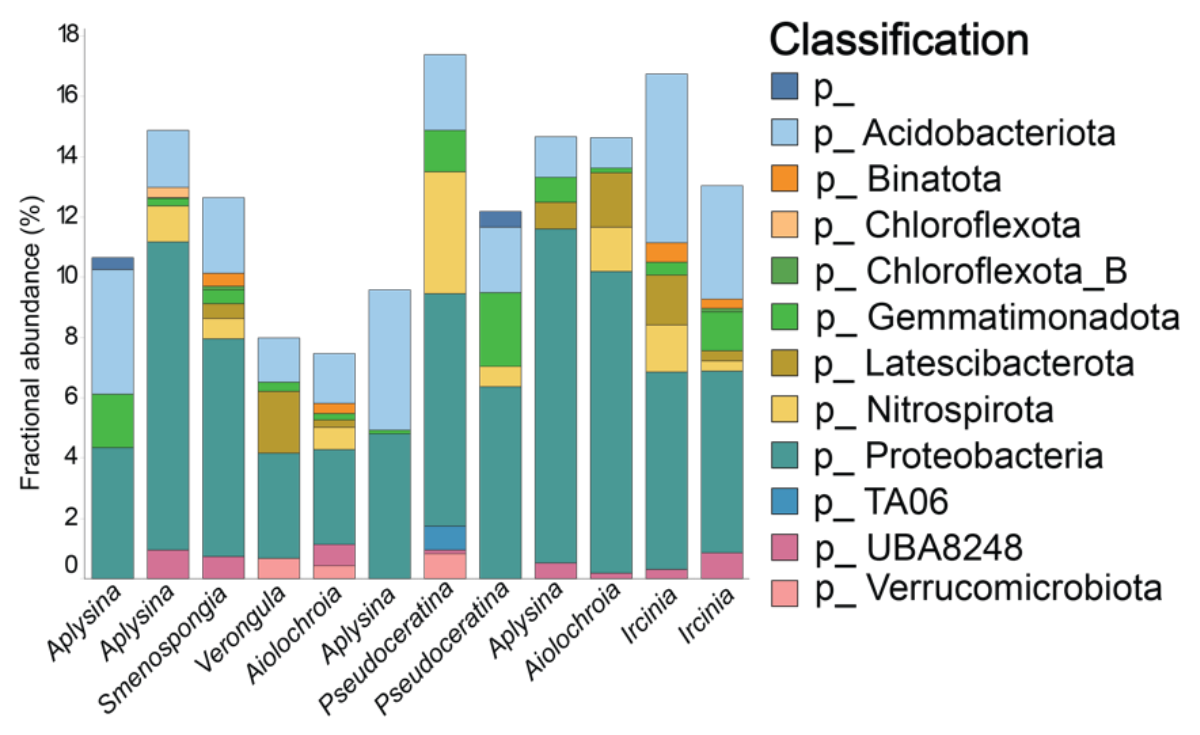

Fig. S3. Fractional abundance of bacteria harboring the $\operatorname{srp}$ BGCs in the respective metagenomes as determined by relative Illumina read abundances. 


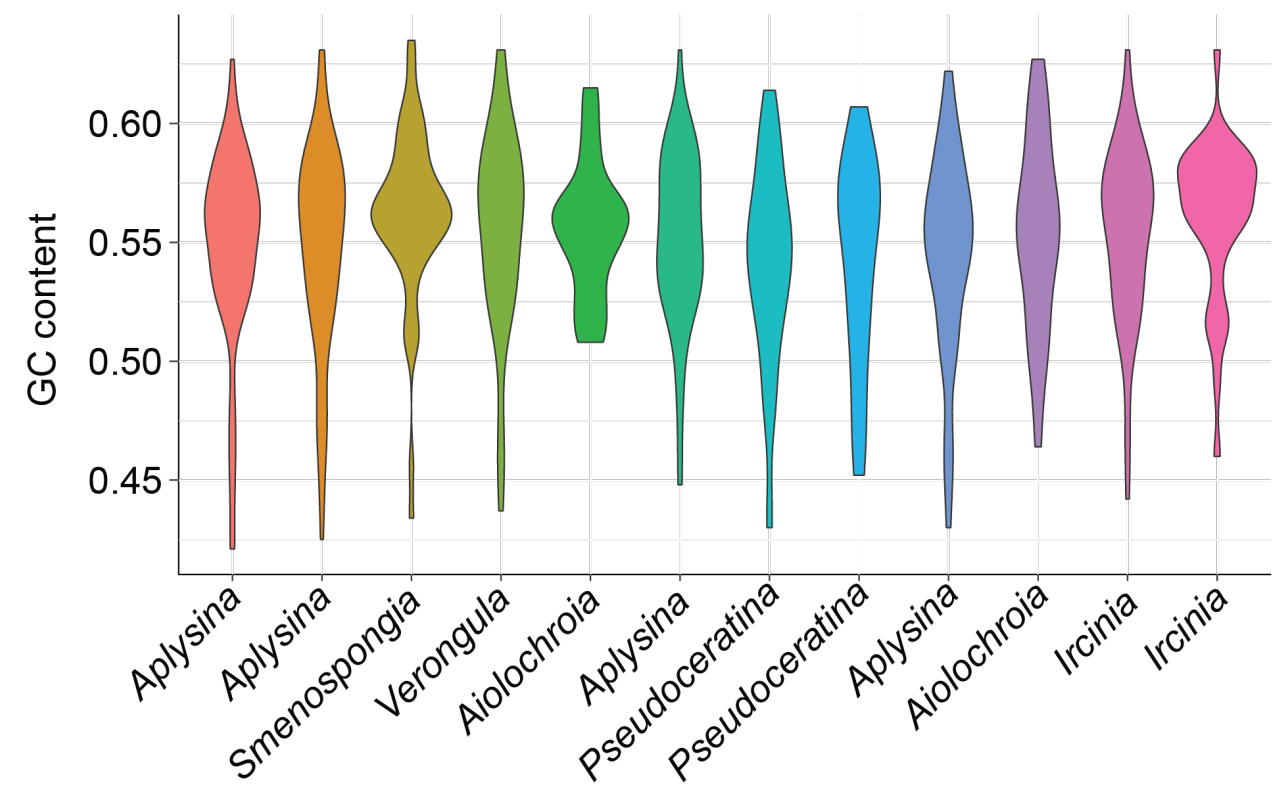

Fig. S4. Violin plot of fractional GC content of all $\operatorname{srp} E$ genes encoded in sponge microbiomes queried in this study. The most frequent GC content of around 55\% is consistent with the presence of srp BGCs in Gammaproteobacteria ${ }^{22}$ and Acidobacteria. ${ }^{23}$ 


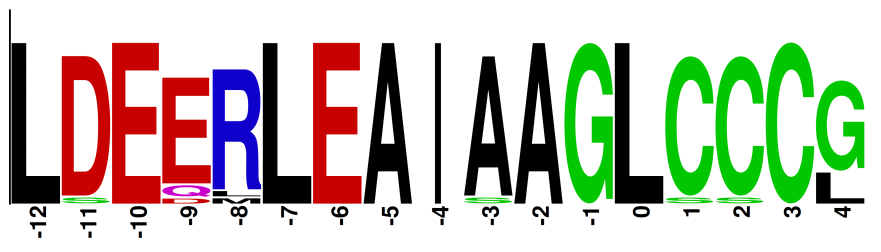

Fig. S5. Weblogo representation of the SrpE core sequences corresponding to the srp BGCs in cluster_3 in Fig. 2C. Note that in place of tryptophan residue that is present at the C-terminus of the $1 \mathrm{SrpE}$ core, the C-termini of the SrpE sequences in cluster_3 contain either a glycine or a leucine residue. 


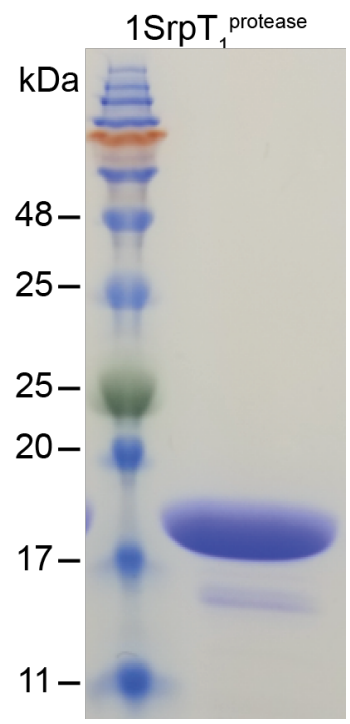

Fig. S6. SDS-PAGE for purified $1 \mathrm{SrpT}_{1}{ }^{\text {protease }}$ by expression in E. coli. 


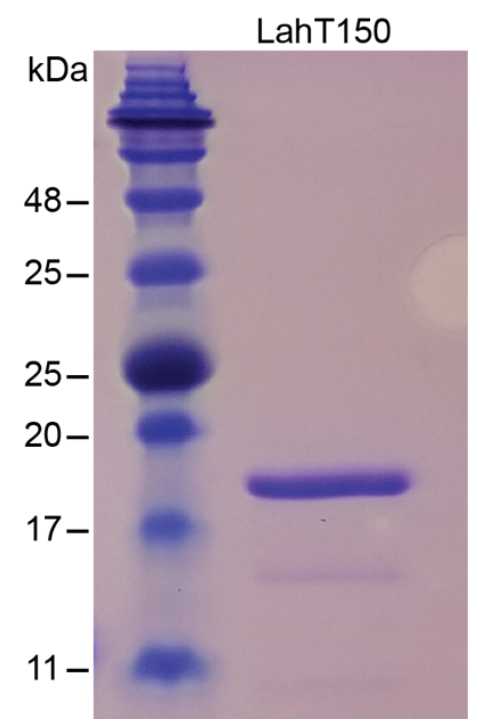

Fig. S7. SDS-PAGE for purified LahT150 by expression in E. coli. 


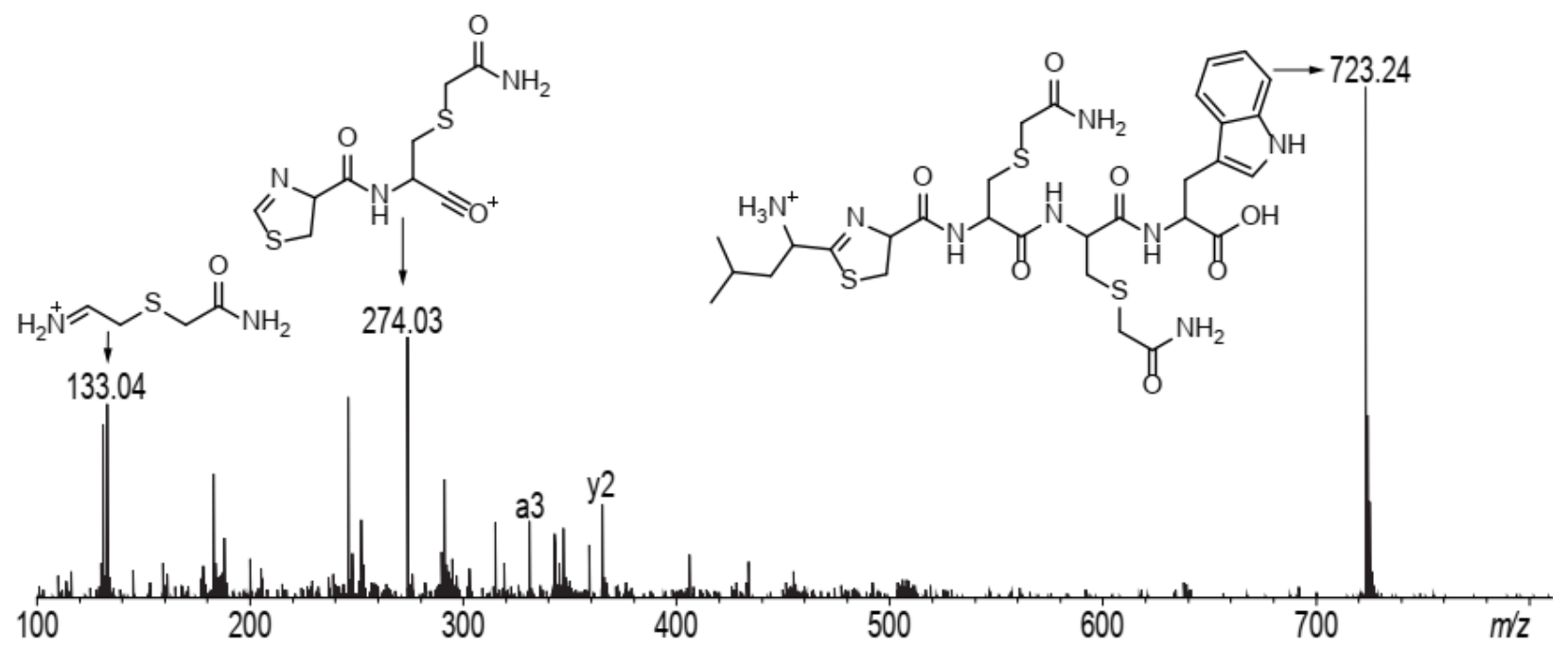

Fig. S8. Structural annotation of the high resolution and high accuracy ESI-ToF MS ${ }^{2}$ fragmentation spectra for the monodehydrated $1 \mathrm{SrpE}$ core obtained by coexpression of $1 \operatorname{srp} E$ with $1 \operatorname{srp} C$ and treatment of the purified product with LahT150 followed by alkylation with iodoacetamide. 


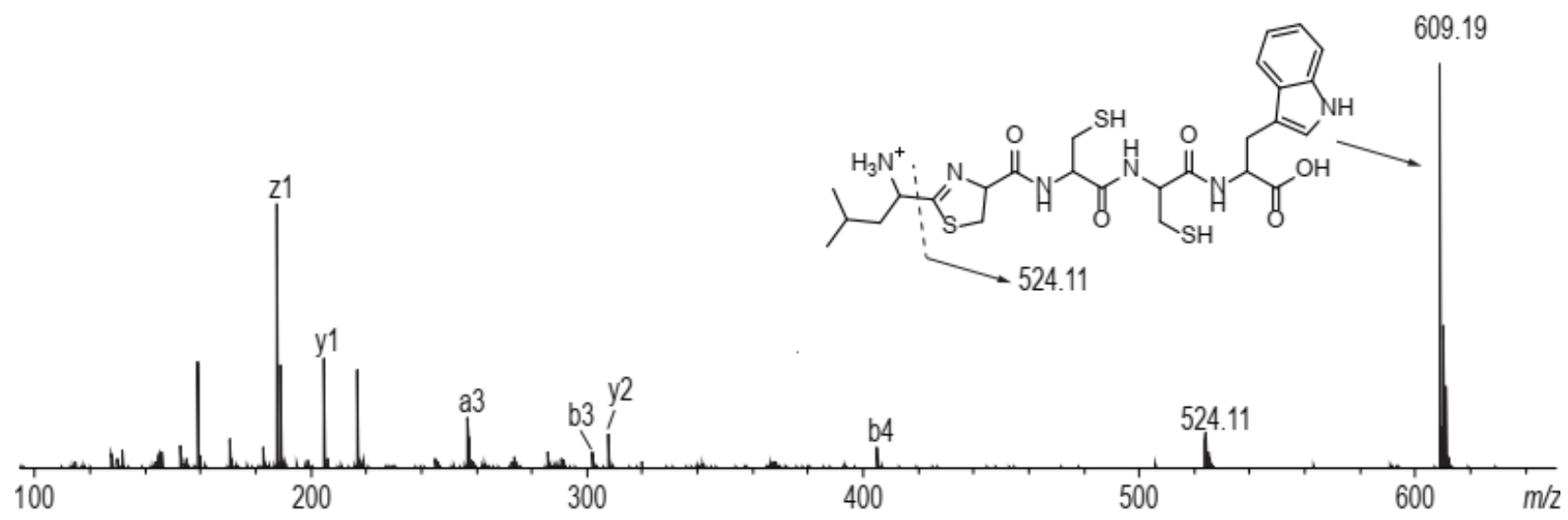

Fig. S9. Structural annotation of the high resolution and high accuracy ESI-ToF MS ${ }^{2}$ fragmentation spectra for the monodehydrated 1 SrpE core obtained by coexpression of $1 \operatorname{srpE}$ with $1 \operatorname{srp} C$ and treatment of the purified product with LahT150. 


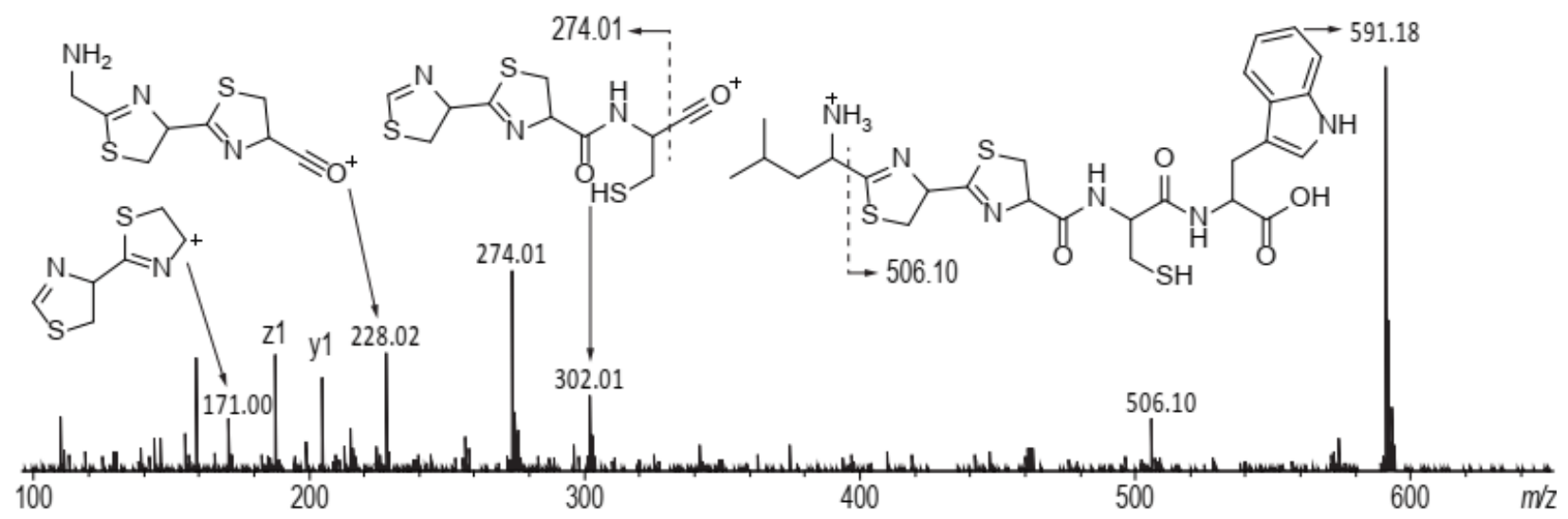

Fig. S10. Structural annotation of the high resolution and high accuracy ESI-ToF MS ${ }^{2}$ fragmentation spectra for the didehydrated $1 \mathrm{SrpE}$ core obtained by coexpression of $1 \operatorname{srp} E$ with $1 \operatorname{srp} C$ and treatment of the purified product with LahT150. 


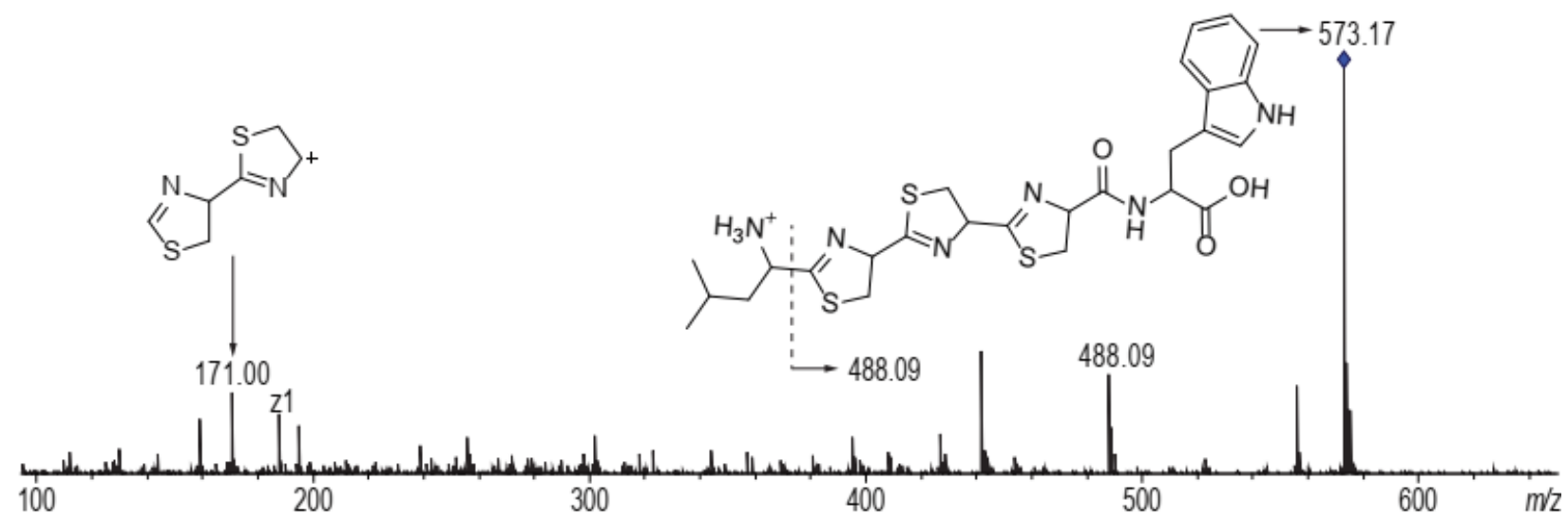

Fig. S11. Structural annotation of the high resolution and high accuracy ESI-ToF $\mathrm{MS}^{2}$ fragmentation spectra for the tridehydrated $1 \mathrm{SrpE}$ core obtained by coexpression of $1 \operatorname{srp} E$ with $1 \operatorname{srp} C$ and treatment of the purified product with LahT150. 


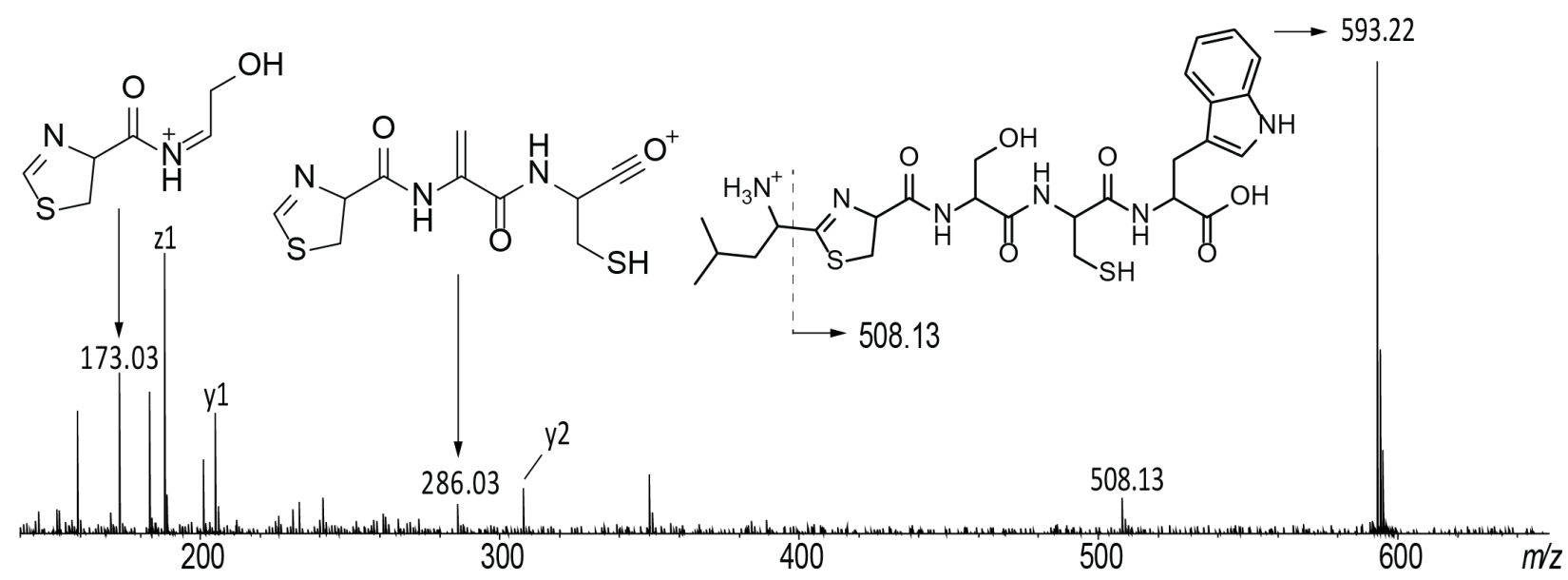

Fig. S12. Structural annotation of the high resolution and high accuracy ESI-ToF $\mathrm{MS}^{2}$ fragmentation spectra for the mono-dehydrated $1 \mathrm{SrpE}$-LCSCW core obtained by coexpression of the mutated $1 \operatorname{srp} E$ (-LCSCW) with $1 \operatorname{srpC}$ and treatment of the purified product with LahT150. 


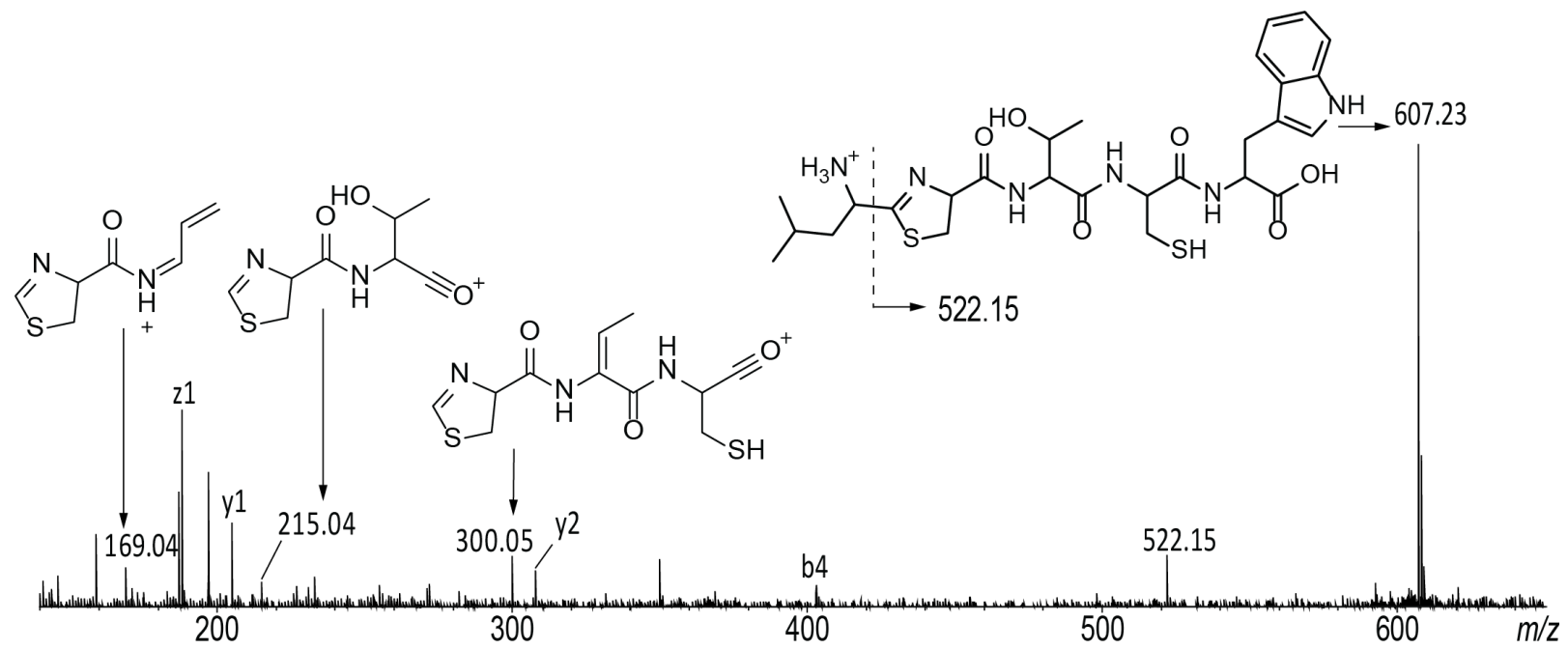

Fig. S13. Structural annotation of the high resolution and high accuracy ESI-ToF $\mathrm{MS}^{2}$ fragmentation spectra for the mono-dehydrated $1 \mathrm{SrpE}$-LCTCW core obtained by coexpression of the mutated $1 \operatorname{srpE}$ (-LCTCW) with $1 \operatorname{srp} C$ and treatment of the purified product with LahT150. 


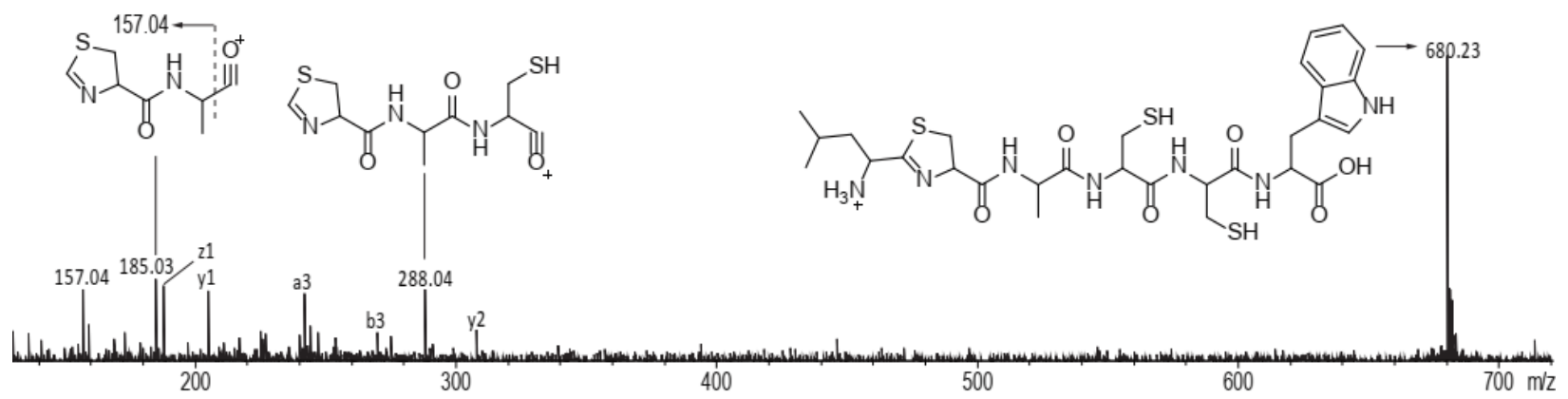

Fig. S14. Structural annotation of the high resolution and high accuracy ESI-ToF $\mathrm{MS}^{2}$ fragmentation spectra for the mono-dehydrated 1SrpE-LCACCW core obtained by coexpression of the mutated 1srpE (-LCACCW) with $1 \operatorname{srp} C$ and treatment of the purified product with LahT150. 


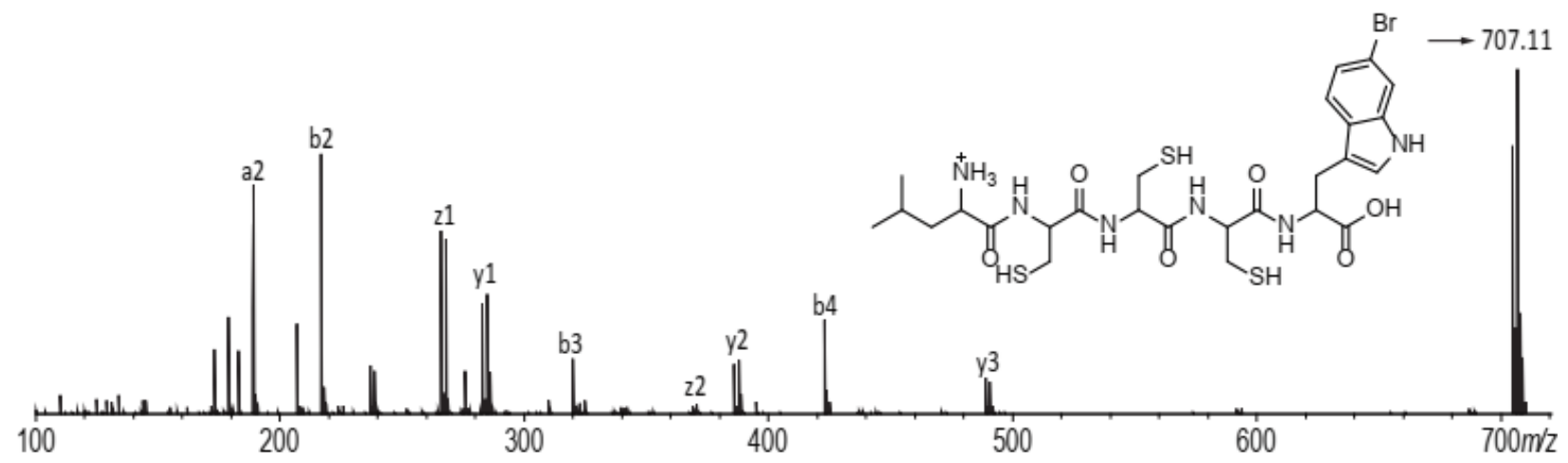

Fig. S15. Structural annotation of the high resolution and high accuracy ESI-ToF $\mathrm{MS}^{2}$ fragmentation spectra for the monobrominated $1 \mathrm{SrpE}$ core obtained by coexpression of the $1 \operatorname{srp} E$ with $1 \operatorname{srpI}$ and treatment of the purified product with LahT150. 


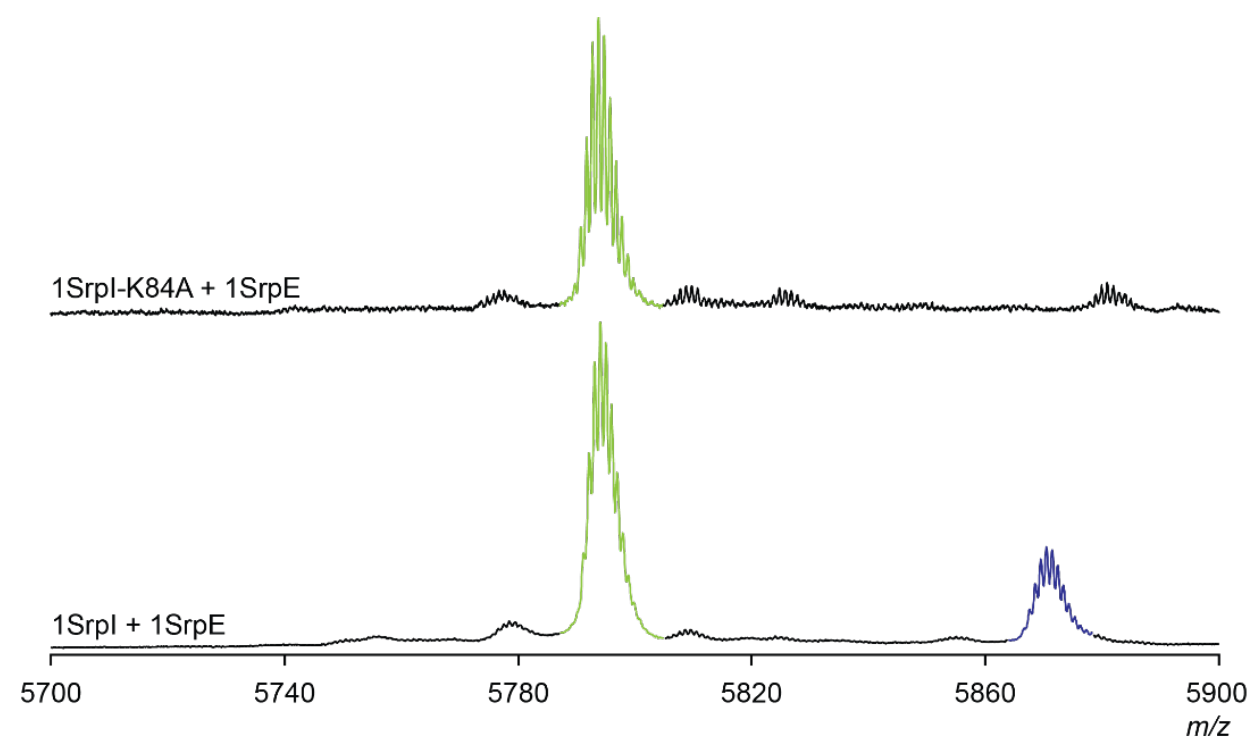

Fig. S16. (bottom) Co-expression of $1 \operatorname{srp} E$ and $1 s r p I$ in $E$. coli leads to production of a monobrominated product (in blue). (top) Co-expression of $1 \operatorname{srpE}$ and mutated $1 \operatorname{srpI}$ in which the catalytic Lys84 residue has been mutated to alanine leads to loss in production of the monobrominated product as monitored by MALDI-ToF MS. 


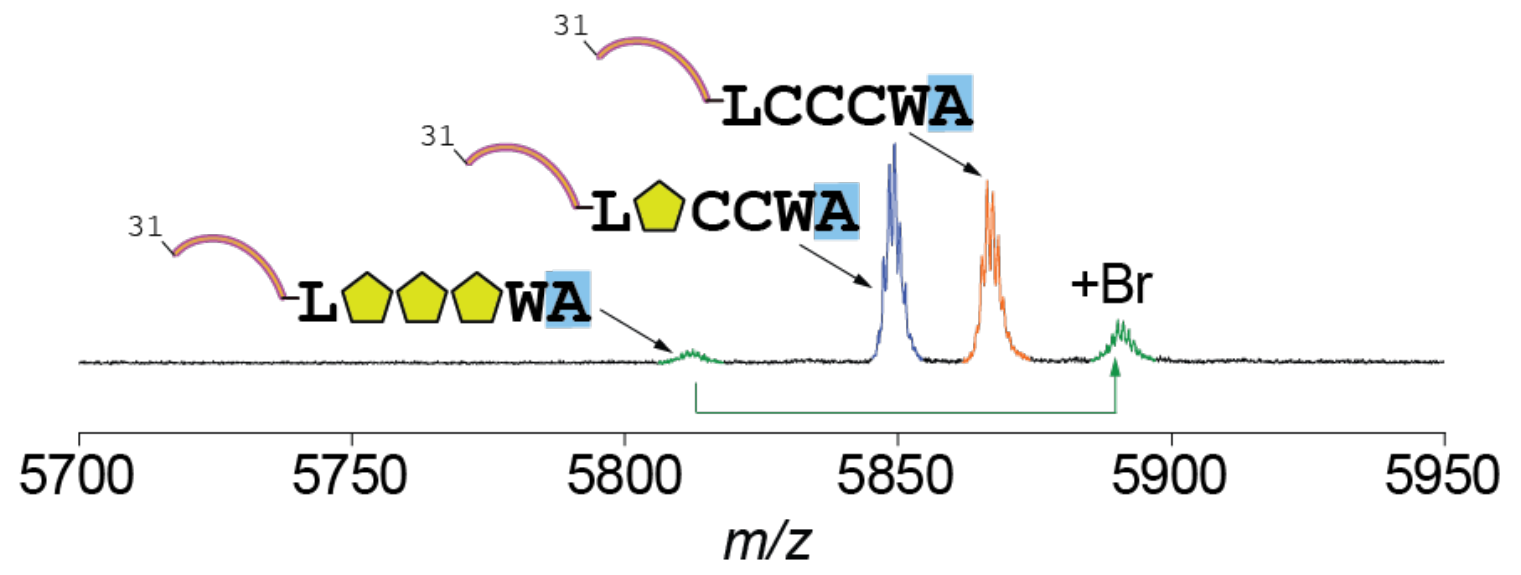

Fig. S17. MALDI-ToF MS spectrum demonstrating the in vivo processing of 1SrpE-LCCCWA by 1 SrpC and $1 \mathrm{SrpE}$ to yield cyclodehydrated and brominated products. 


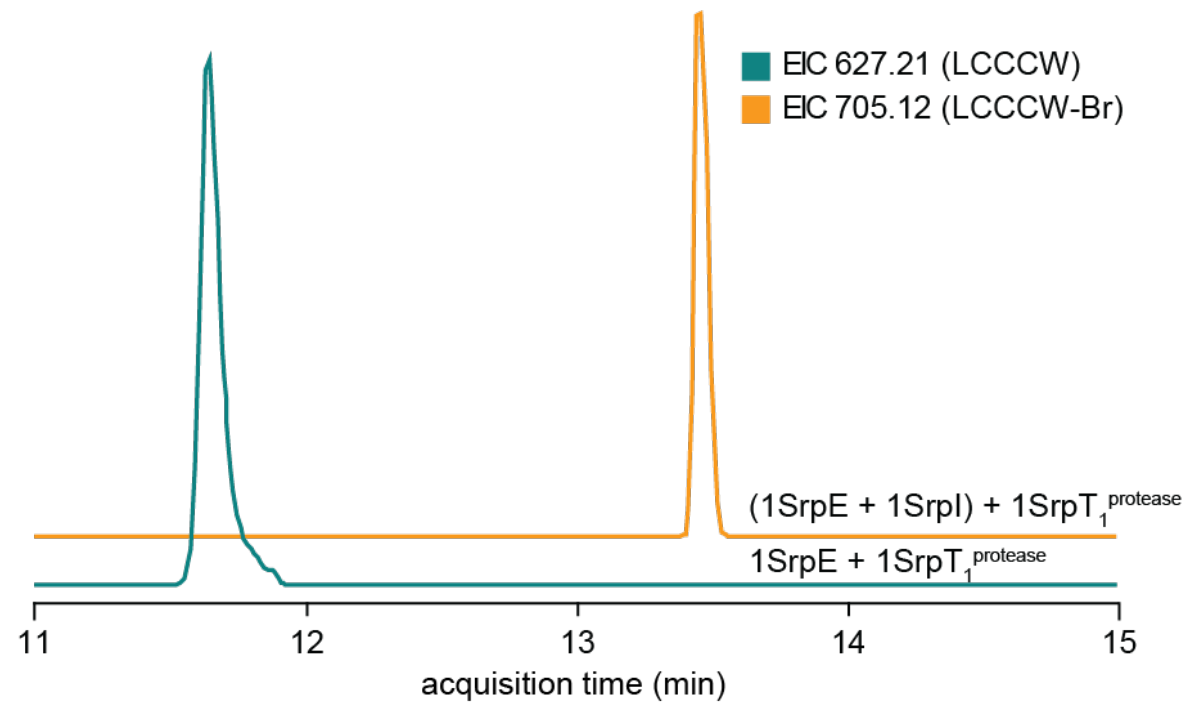

Fig. S18. LC/MS extracted ion chromatograms (EICs) demonstrating the production of the pentapeptide LCCCW product upon incubation of $1 \mathrm{SrpE}$ with $1 \mathrm{SrpT}_{1}{ }^{\text {protease }}$, and the production of the monobrominated pentapeptide product when $1 \mathrm{SrpE}$ that had been modified by $1 \mathrm{SrpI}$ was incubated with $1 \mathrm{SrpT}_{1}{ }^{\text {protease }}$. 


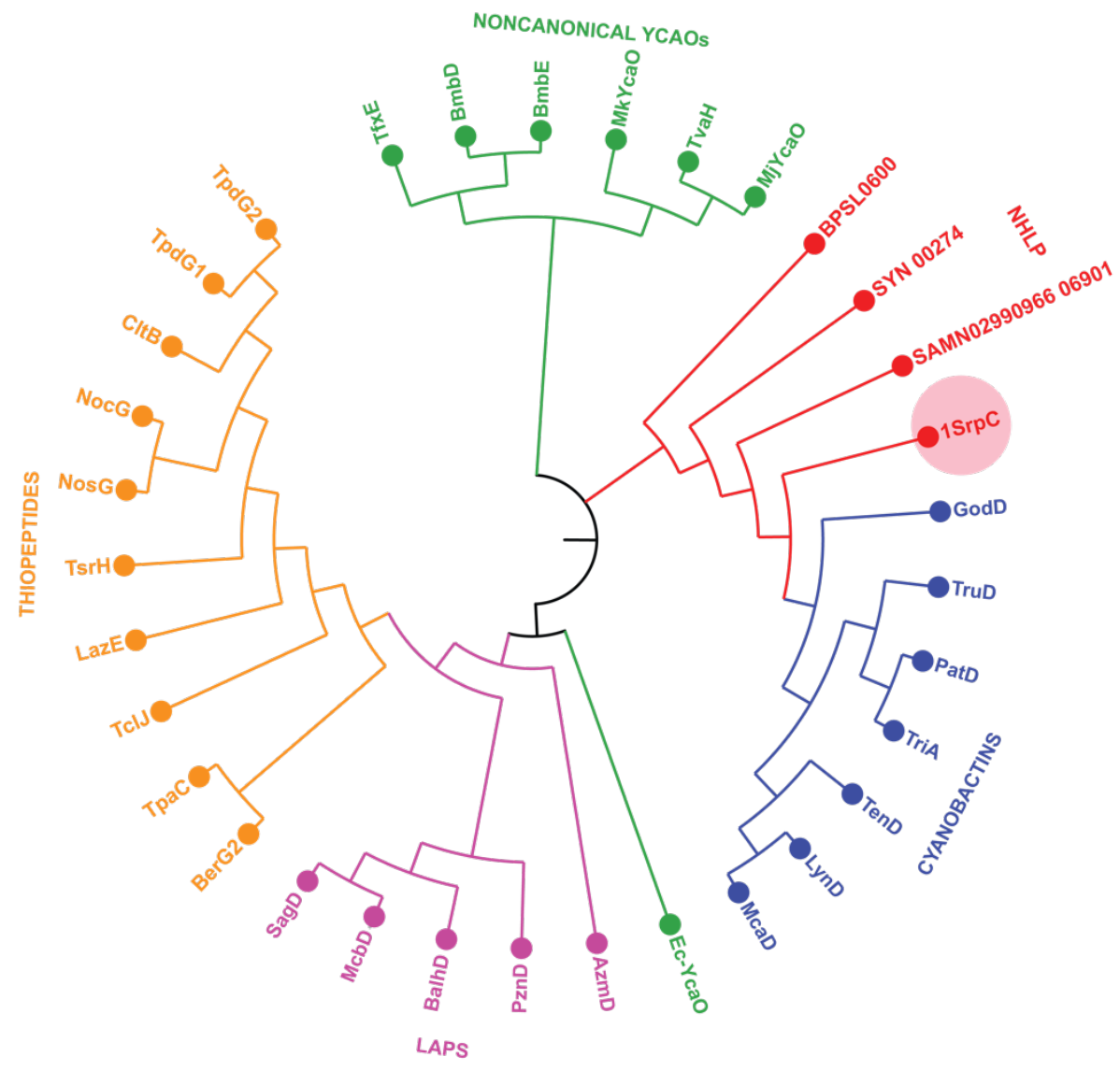

Fig. S19. Sequence similarity of SrpC (red, circled) to other YcaOs that participate in RiPP biosynthesis. 


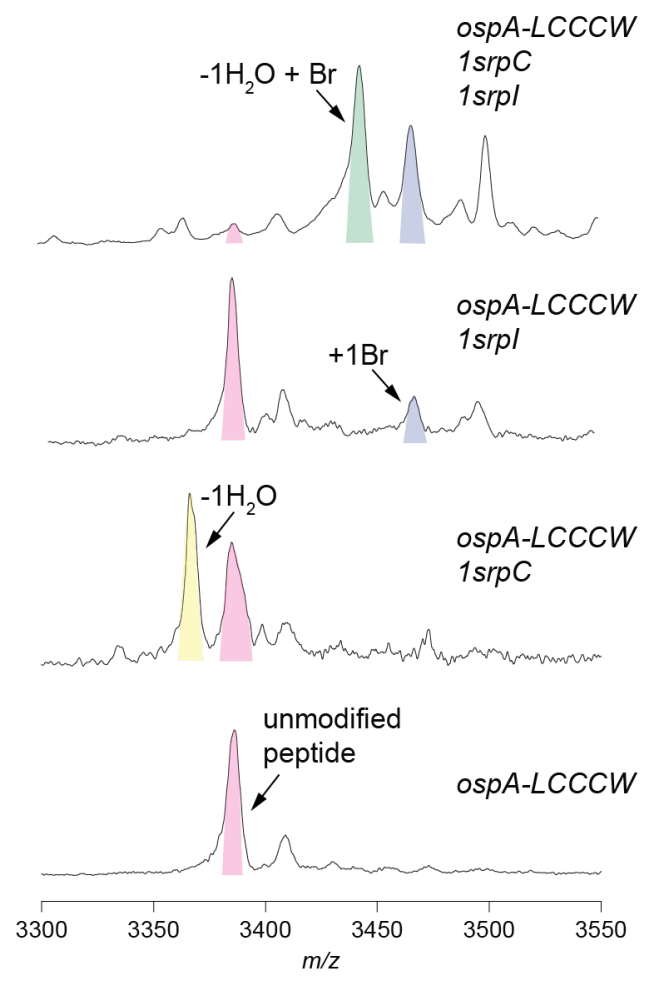

Fig. S20. Cyclodehydration and bromination of OspA-LCCCW substrate observed upon coexpression of $1 \operatorname{srpC}$, $1 \operatorname{srpI}$, and $\operatorname{sp} A-L C C C W$. Reactions are monitored by MALDI-ToF MS in the linear mode. 


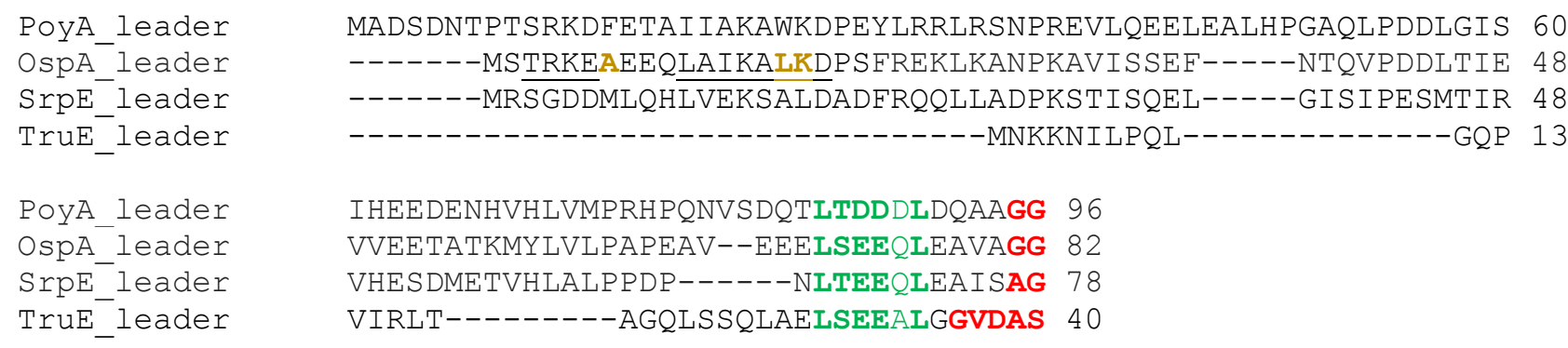

Fig. S21. Sequence alignment between leader sequences of the proteusin substrates PoyA, OspA, and SrpE, and the cyanobactin TruE. The recognition sequence directing activity of the YcaO cyclodehydratases is highlighted in green. Residues immediately preceding the core are highlighted in red. For the cyanobactins, the GVDAS sequence guides the activity of the protease that cleaves at the leader/core boundary. Regions in the OspA leader that have been shown to guide the activity of the amino acid $\mathrm{C} \alpha$ epimerase are underlined. The OspA leader residues, mutation of which led to large decrease in epimerization activity are highlighted in brown. 


\section{SUPPLEMENTARY REFERENCES}

1. Joshi, N. A.; Fass, J. N. Sickle: A sliding-window, adaptive, quality-based trimming tool for FASTQ files (Version 1.33) https://github.com/najoshi/sickle.

2. Bushnell, B.; Rood, J.; Singer, E., BBMerge - Accurate paired shotgun read merging via overlap. PLoS One 2017, 12 (10), e0185056.

3. Bankevich, A.; Nurk, S.; Antipov, D.; Gurevich, A. A.; Dvorkin, M.; Kulikov, A. S.; Lesin, V. M.; Nikolenko, S. I.; Pham, S.; Prjibelski, A. D.; Pyshkin, A. V.; Sirotkin, A. V.; Vyahhi, N.; Tesler, G.; Alekseyev, M. A.; Pevzner, P. A., SPAdes: a new genome assembly algorithm and its applications to single-cell sequencing. $J$. Comput. Biol. 2012, 19 (5), 455-477.

4. Nurk, S.; Bankevich, A.; Antipov, D.; Gurevich, A. A.; Korobeynikov, A.; Lapidus, A.; Prjibelski, A. D.; Pyshkin, A.; Sirotkin, A.; Sirotkin, Y.; Stepanauskas, R.; Clingenpeel, S. R.; Woyke, T.; Mclean, J. S.; Lasken, R.; Tesler, G.; Alekseyev, M. A.; Pevzner, P. A., Assembling Single-Cell Genomes and Mini-Metagenomes From Chimeric MDA Products. J. Comput. Biol. 2013, 20 (10), 714-737.

5. Miller, I. J.; Rees, E. R.; Ross, J.; Miller, I.; Baxa, J.; Lopera, J.; Kerby, R. L.; Rey, F. E.; Kwan, J. C., Autometa: automated extraction of microbial genomes from individual shotgun metagenomes. Nucleic Acids Res. 2019, 47 (10), e57.

6. Chaumeil, P. A.; Mussig, A. J.; Hugenholtz, P.; Parks, D. H., GTDB-Tk: a toolkit to classify genomes with the Genome Taxonomy Database. Bioinformatics 2020, 36(6), 1925-1927.

7. Varghese, N. J.; Mukherjee, S.; Ivanova, N.; Konstantinidis, K. T.; Mavrommatis, K.; Kyrpides, N. C.; Pati, A., Microbial species delineation using whole genome sequences. Nucleic Acids Res. 2015, 43 (14), 6761-6771.

8. Altamia, M. A.; Lin, Z.; Trindade-Silva, A. E.; Uy, I. D.; Shipway, J. R.; Wilke, D. V.; Concepcion, G. P.; Distel, D. L.; Schmidt, E. W.; Haygood, M. G., Secondary metabolism in the gill microbiota of shipworms (Teredinidae) as revealed by comparison of metagenomes and nearly complete symbiont genomes. $m$ Systems $\mathbf{2 0 2 0}$, 5 (3), e00261-20.

9. $\quad$ Blin, K.; Wolf, T.; Chevrette, M. G.; Lu, X.; Schwalen, C. J.; Kautsar, S. A.; Suarez Duran, H. G.; de Los Santos, E. L. C.; Kim, H. U.; Nave, M.; Dickschat, J. S.; Mitchell, D. A.; Shelest, E.; Breitling, R.; Takano, E.; Lee, S. Y.; Weber, T.; Medema, M. H., antiSMASH 4.0-improvements in chemistry prediction and gene cluster boundary identification. Nucleic Acids Res. 2017, 45 (W1), W36-W41.

10. Shannon, P.; Markiel, A.; Ozier, O.; Baliga, N. S.; Wang, J. T.; Ramage, D.; Amin, N.; Schwikowski, B.; Ideker, T., Cytoscape: a software environment for integrated models of biomolecular interaction networks. Genome Res. 2003, 13 (11), 2498-504. 
11. Mohanty, I.; Podell, S.; Biggs, J. S.; Garg, N.; Allen, E. E.; Agarwal, V., Multi-omic profiling of Melophlus sponges reveals diverse metabolomic and microbiome architectures that are non-overlapping with ecological neighbors. Mar. Drugs 2020, 18 (2), 124.

12. Mohanty, I.; Moore, S. G.; Yi, D.; Biggs, J. S.; Gaul, D. A.; Garg, N.; Agarwal, V., Precursor-guided mining of marine sponge metabolomes lends insight into biosynthesis of pyrrole-imidazole alkaloids. ACS Chem. Bio. 2020, $15(8), 2185-2194$.

13. Bolyen, E.; Rideout, J. R.; Dillon, M. R.; Bokulich, N. A.; Abnet, C. C.; Al-Ghalith, G. A.; Alexander, H.; Alm, E. J.; Arumugam, M.; Asnicar, F.; Bai, Y.; Bisanz, J. E.; Bittinger, K.; Brejnrod, A.; Brislawn, C. J.; Brown, C. T.; Callahan, B. J.; Caraballo-Rodríguez, A. M.; Chase, J.; Cope, E. K.; Da Silva, R.; Diener, C.; Dorrestein, P. C.; Douglas, G. M.; Durall, D. M.; Duvallet, C.; Edwardson, C. F.; Ernst, M.; Estaki, M.; Fouquier, J.; Gauglitz, J. M.; Gibbons, S. M.; Gibson, D. L.; Gonzalez, A.; Gorlick, K.; Guo, J.; Hillmann, B.; Holmes, S.; Holste, H.; Huttenhower, C.; Huttley, G. A.; Janssen, S.; Jarmusch, A. K.; Jiang, L.; Kaehler, B. D.; Kang, K. B.; Keefe, C. R.; Keim, P.; Kelley, S. T.; Knights, D.; Koester, I.; Kosciolek, T.; Kreps, J.; Langille, M. G. I.; Lee, J.; Ley, R.; Liu, Y.-X.; Loftfield, E.; Lozupone, C.; Maher, M.; Marotz, C.; Martin, B. D.; McDonald, D.; McIver, L. J.; Melnik, A. V.; Metcalf, J. L.; Morgan, S. C.; Morton, J. T.; Naimey, A. T.; Navas-Molina, J. A.; Nothias, L. F.; Orchanian, S. B.; Pearson, T.; Peoples, S. L.; Petras, D.; Preuss, M. L.; Pruesse, E.; Rasmussen, L. B.; Rivers, A.; Robeson, M. S.; Rosenthal, P.; Segata, N.; Shaffer, M.; Shiffer, A.; Sinha, R.; Song, S. J.; Spear, J. R.; Swafford, A. D.; Thompson, L. R.; Torres, P. J.; Trinh, P.; Tripathi, A.; Turnbaugh, P. J.; Ul-Hasan, S.; van der Hooft, J. J. J.; Vargas, F.; Vázquez-Baeza, Y.; Vogtmann, E.; von Hippel, M.; Walters, W.; Wan, Y.; Wang, M.; Warren, J.; Weber, K. C.; Williamson, C. H. D.; Willis, A. D.; Xu, Z. Z.; Zaneveld, J. R.; Zhang, Y.; Zhu, Q.; Knight, R.; Caporaso, J. G., Reproducible, interactive, scalable and extensible microbiome data science using QIIME 2. Nat. Biotechnol. 2019, $37(8), 852-857$.

14. Callahan, B. J.; McMurdie, P. J.; Rosen, M. J.; Han, A. W.; Johnson, A. J. A.; Holmes, S. P., DADA2: high-resolution sample inference from Illumina amplicon data. Nat. Methods 2016, 13 (7), 581-583.

15. Yilmaz, P.; Parfrey, L. W.; Yarza, P.; Gerken, J.; Pruesse, E.; Quast, C.; Schweer, T.; Peplies, J.; Ludwig, W.; Glöckner, F. O., The SILVA and "All-species Living Tree Project (LTP)" taxonomic frameworks. Nucleic Acids Res. 2014, 42 (Database issue), D643-D648.

16. Bhandari, D. M.; Fedoseyenko, D.; Begley, T. P., Mechanistic studies on tryptophan lyase (NosL): identification of cyanide as a reaction product. J. Am. Chem. Soc. 2018, 140 (2), 542-545.

17. Romney, D. K.; Murciano-Calles, J.; Wehrmüller, J. E.; Arnold, F. H., Unlocking reactivity of TrpB: a general biocatalytic platform for synthesis of tryptophan analogues. J. Am. Chem. Soc. 2017, 139 (31), 1076910776. 
18. Mohanty, I.; Tapadar, S.; Moore, S. G.; Biggs, J. S.; Freeman, C. J.; Gaul, D. A.; Garg, N.; Agarwal, V., Presence of bromotyrosine alkaloids in marine sponges is independent of metabolomic and microbiome architectures. mSystems 2021, 6 (2), e01387-20.

19. Cantrell, T. P.; Freeman, C. J.; Paul, V. J.; Agarwal, V.; Garg, N., Mass spectrometry-based integration and expansion of the chemical diversity harbored within a marine sponge. J. Am. Soc. Mass Spectrom. 2019, 30, 13731384.

20. Mohanty, I.; Moore, S. G.; Yi, D.; Biggs, J. S.; Gaul, D. A.; Garg, N.; Agarwal, V., Precursor-guided mining of marine sponge metabolomes lends insight into biosynthesis of pyrrole-imidazole alkaloids. ACS Chem. Biol. 2020, 15 (8), 2185-2194.

21. Mohanty, I.; Podell, S.; Biggs, S. J.; Garg, N.; Allen, E. E.; Agarwal, V., Multi-omic profiling of Melophlus sponges reveals diverse metabolomic and microbiome architectures that are non-overlapping with ecological neighbors. Mar. Drugs 2020, 18 (2), 124.

22. Lightfield, J.; Fram, N. R.; Ely, B., Across bacterial phyla, distantly-related genomes with similar genomic GC content have similar patterns of amino acid usage. PLOS ONE 2011, 6 (3), e17677.

23. Eichorst, S. A.; Trojan, D.; Roux, S.; Herbold, C.; Rattei, T.; Woebken, D., Genomic insights into the Acidobacteria reveal strategies for their success in terrestrial environments. Environ. Microbiol. 2018, 20 (3), 10411063. 